\title{
Characterizing the unmet HIV prevention needs and HIV risk vulnerabilities of adolescent girls and young women in Ethiopia
}

Carly A. Comins

Sheree Schwartz

Stefan Baral

Andargachew Mulu

Follow this and additional works at: https://knowledgecommons.popcouncil.org/departments_sbsr-hiv

Part of the Public Health Commons

How does access to this work benefit you? Let us know!

\section{Recommended Citation}

Comins, Carly A., Sheree Schwartz, Stefan Baral, and Andargachew Mulu. 2020. "Characterizing the unmet HIV prevention needs and HIV risk vulnerabilities of adolescent girls and young women in Ethiopia,"

Project SOAR Final Report. Washington, DC: USAID I Project SOAR. 


\section{Characterizing the Unmet \\ $\frac{1}{6}$ HIV Prevention Needs and HIV Risk Vulnerabilities of Adolescent Girls and Young Women in Ethiopia}

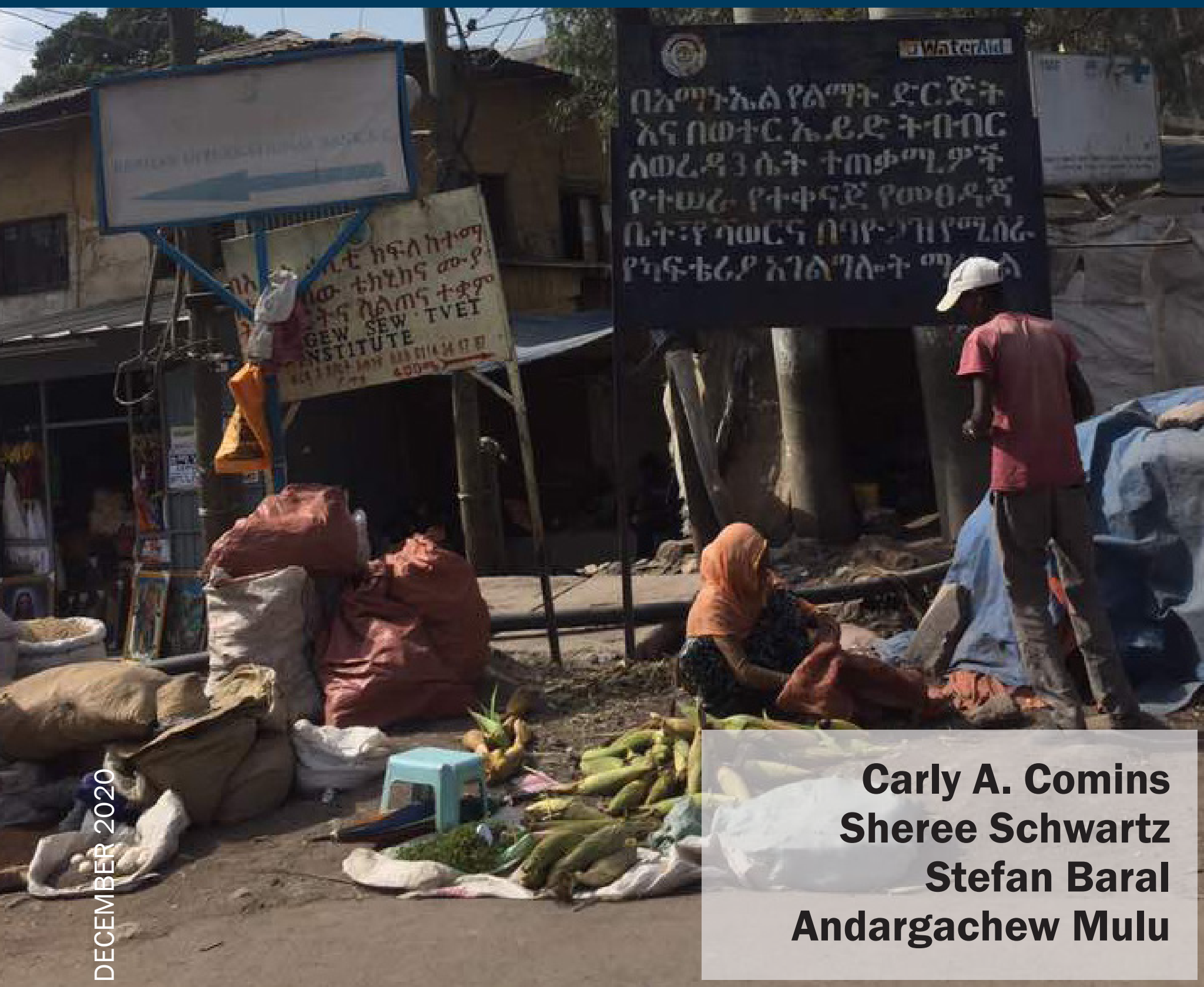

瑟 PEPFÁR 
Project SOAR

Population Council

4301 Connecticut Ave, NW, Suite 280

Washington, D.C. 20008 USA

Tel: +1202 2379400

Fax: +1202 2378410

projsoar.org
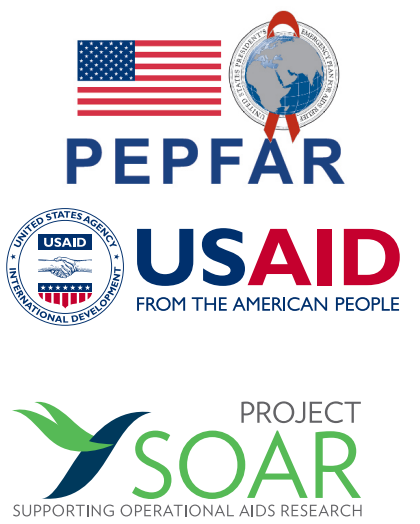

\section{- POPULATION COUNCIL}

Ideas. Evidence. Impact.
Project SOAR (Cooperative Agreement AID-OAA-A-14-00060) is made possible by the generous support of the American people through the United States President's Emergency Plan for AIDS Relief and the United States Agency for International Development (USAID). The contents of this report are the sole responsibility of Project SOAR and the Population Council and do not necessarily reflect the views of PEPFAR, USAID, or the United States Government.

Through operations research, Project SOAR will determine how best to address challenges and gaps that remain in the delivery of HIV and AIDS care and support, treatment, and prevention services. Project SOAR will produce a large, multifaceted body of high-quality evidence to guide the planning and implementation of HIV and AIDS programs and policies. Led by the Population Council, Project SOAR is implemented in collaboration with Avenir Health, Elizabeth Glaser Pediatric AIDS Foundation, Johns Hopkins University, Palladium, and The University of North Carolina.

The Population Council confronts critical health and development issues-from stopping the spread of HIV to improving reproductive health and ensuring that young people lead full and productive lives. Through biomedical, social science and public health research in about 50 countries, the Council works with our partners to deliver solutions that lead to more effective policies, programs, and technologies to improve lives worldwide. Established in 1952 and headquartered in New York, the Council is a nongovernmental, nonprofit organization with an international board of trustees.

Cover photo credit: @ Hanna Alemayehu/Armauer Hansen Research Institute

Published in December 2020. (C2020 The Population Council Inc.

Suggested citation: Comins, Carly A., Sheree Schwartz, Stefan Baral, and Andargachew Mulu. 2020. "Characterizing the unmet HIV prevention needs and HIV risk vulnerabilities of adolescent girls and young women in Ethiopia," Project SOAR Final Report. Washington, DC: USAID | Project SOAR. 


\section{Characterizing the Unmet HIV Prevention Needs and HIV Risk Vulnerabilities of Adolescent Girls and Young Women in Ethiopia}

Carly A. Comins ${ }^{1}$, Sheree Schwartz ${ }^{1}$, Stefan Baral ${ }^{1}$, Andargachew Mulu²

${ }^{1}$ Johns Hopkins University

${ }^{2}$ Armauer Hansen Research Institute 


\section{ACKNOWLEDGEMENTS}

We thank the study participants for their time, commitment, and contribution to this work. We thank study staff and health facility staff at the study sites. We thank the collaboration from all study partners including Armauer Hansen Research Institute, USAID Washington and Ethiopia, the Project SOAR team, Population Council, and the Johns Hopkins Bloomberg School of Public Health Key Populations Program. Furthermore, we thank the Ethiopian Regional Health Bureaus, the Federal HIV/AIDS Prevention and Control Office, and city administrations in Addis Ababa, Bahir Dar, and Gambella. 


\section{TABLE OF CONTENTS}

ACKNOWLEDGEMENTS

ABBREVIATIONS AND ACRONYMS ................................................................................

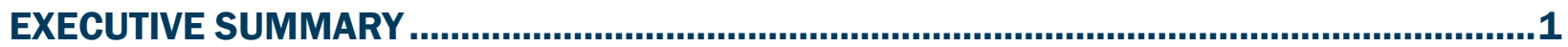

BACKGROUND AND RATIONALE

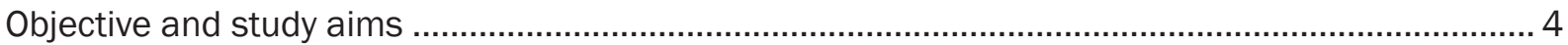

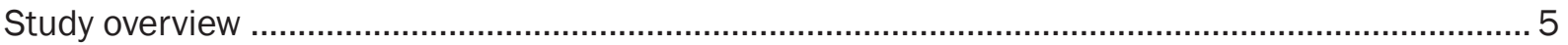

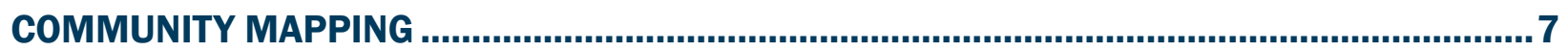

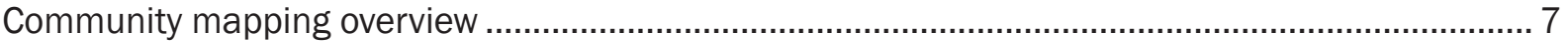

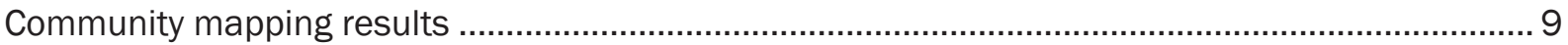

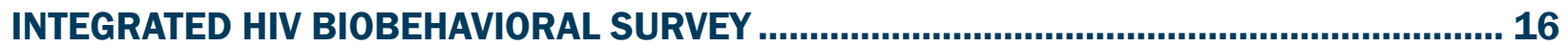

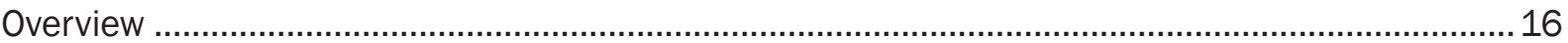

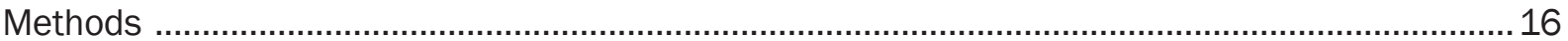

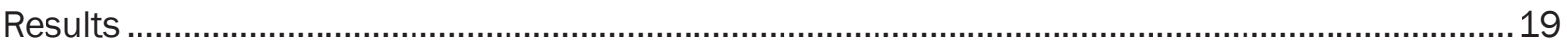

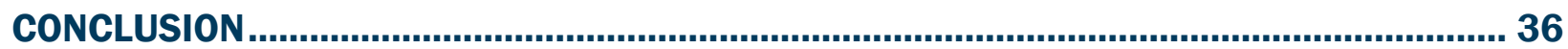

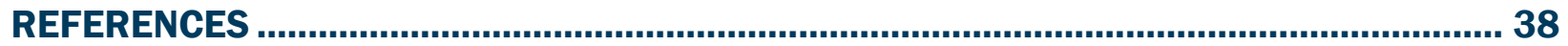

APPENDIX 1 HEALTH FACILITIES MAPPED IN ADDIS ABABA, BAHIR DAR, AND

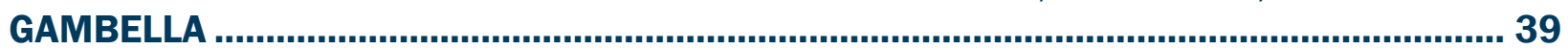




\section{ABBREVIATIONS AND ACRONYMS}

$\begin{array}{ll}\text { AGYW } & \text { Adolescent girls and young women } \\ \text { AHRI } & \text { Armauer Hansen Research Institute } \\ \text { AWSA } & \text { Attitudes Toward Women Scale for Adolescents } \\ \text { CAB } & \text { Community advisory board } \\ \text { CAG } & \text { Community advisory group } \\ \text { DHS } & \text { Demographic and Health Survey } \\ \text { FHAPCO } & \text { Federal HIV/AIDS Prevention and Control Office } \\ \text { FSW } & \text { Female sex worker } \\ \text { IBBS } & \text { Integrated HIV Biobehavioral Survey } \\ \text { JHU } & \text { Johns Hopkins University } \\ \text { KI } & \text { Key informant } \\ \text { MoH } & \text { Ministry of Health } \\ \text { SSA } & \text { Sub-Saharan Africa } \\ \text { USAID } & \text { Time location sampling } \\ & \text { U.S. Agency for International Development } \\ & \end{array}$




\section{EXECUTIVE SUMMARY}

From 21 February 2018 to 9 July 2019, Armauer Hansen Research Institute (AHRI) and Johns Hopkins Bloomberg School of Public Health through Project SOAR in consultation with USAID Ethiopia conducted an integrated HIV biobehavioral survey (IBBS) focused on out-of-school adolescent girls and young women (AGYW) aged 15-24 years. The purpose of the IBBS was to estimate HIV and STI prevalence among AGYW and to assess HIV risk vulnerability. Prior to conducting the IBBS, formative work mapped potential recruitment locations to reach out-ofschool AGYW. Stakeholder engagement was also conducted, including engagement with the Federal HIV/AIDS Prevention and Control Office (FHAPCO), to ensure that the IBBS filled identified data gaps.

AGYW are a priority population across sub-Saharan Africa, which experiences a disproportionate HIV prevalence and incidence. Although the disparity in HIV prevalence among young women and their male counterparts is not new, there is increasing recognition that addressing the unmet HIV prevention needs among AGYW is necessary to achieve epidemic control. In Ethiopia, data characterizing unmet HIV prevention needs and HIV risk vulnerabilities among AGYW, particularly out of school AGYW, have been limited.

The aims of this research included: i) understanding through community mapping and key informant interviews where to find and recruit AGYW, ii) characterizing risks and vulnerabilities faced by AGYW in Ethiopia to inform future HIV prevention programming, iii) estimating the HIV prevalence of AGYW in three high HIV prevalence settings in Ethiopia, iv) measuring the burden of STIs among AGYW, including syphilis and chlamydia, and identifying and mapping health facilities across the three settings of Addis Ababa, Bahir Dar, and Gambella.

The work was planned for three areas with elevated HIV prevalence: Addis Ababa in the center of the country; Bahir Dar, a city located in the Amhara region in the northwest of the country; and Gambella in the southwest of the country. Venue and health facility mapping activities were completed in all three areas. In Addis Ababa, a total of 33 health facilities were identified and mapped in three sub-cities: Addis Ketema, Akaky Kaliti, and Kolfe Keranio A total of 2,486 unique venues were identified through 688 key informant (KI) discussions; 802 venues were selected for verification and, of these, 371 (46\%) were determined eligible for sampling. A total of 800 AGYW were recruited across 81 randomly selected eligible venues for data collection. In Bahir Dar, a total of six health facilities were identified and mapped. Of the 856 unique venues identified through $221 \mathrm{KI}$ discussions, 277 were selected for verification and, of these, 177 (63\%) were determined eligible. Of the 177 eligible venues, 37 were randomly sampled for data collection, but due to events occurring in Bahir Dar which altered the risk assessment of the study, data collection activities did not continue. In Gambella, a total of six health facilities were identified and mapped. There were 306 unique venues identified through $108 \mathrm{KI}$ discussions. All 306 were selected for verification and, of these, 211 (68\%) were determined to be eligible. A total of 701 AGYW were recruited across the 44 randomly selected venues for data collection. AGYW aged 15-24 years and living in the cities of Addis Ababa and Gambella were eligible to participate. 
Of the 1,501 AGYW enrolled across the two cities, 53 percent were from Addis Ababa and 47 percent were from Gambella. The mean age of AGYW enrolled was 19.9 years (sd \pm 2.5$), 64$ percent were out-of-school, and 64 percent reported a prior migration into the city. Overall, 73 percent were unemployed or informally employed and half reported renting. A total of 64 percent of AGYW enrolled reported ever having sex, and the mean age of sexual debut was 16.8 years (sd \pm 2.5 ). Consistent condom use for vaginal sexual acts in the prior 12 months was low at 17 percent. Sixteen percent of AGYW reported being married or living together as if married, and a total of 24 percent of AGYW enrolled reported ever being pregnant. Among the 1,501 AGYW enrolled, 12 percent reported engagement in transactional sex (exchanging sexual services for goods, services, or money), which was higher among AGYW aged 20-24 years (131/809, 16\%) than $15-19$ years $(44 / 690,6 \%)$.

The HIV prevalence overall was 2.7 percent (95\% Cl 2.0-3.6) $(2.1 \%$ in Addis Ababa [95\% Cl 1.3-3.4] and 3.3 percent in Gambella [95\% $\mathrm{Cl} 2.2-4.9]$,). Among all AGYW enrolled, the syphilis prevalence was 2.4 percent $(95 \% \mathrm{Cl} 1.7-3.3)$ and the chlamydia prevalence was 5.4 percent (95\% $\mathrm{Cl} 4.3-6.7)$. The prevalence of any STI (HIV, syphilis, or chlamydia) among all study participants was 10 percent (95\% Cl 8.6-11.7\%). In terms of co-infections, 6 out of 151 (4\%) AGYW with an STI were co-infected; all AGYW with a co-infection were living with HIV, 4 with a syphilis co-infection and 2 with a chlamydia co-infection.

These data suggest that venue-based methods used to reach marginalized and predominantly out-of-school AGYW successfully reached young women at increased risk and vulnerability for HIV and STIs in Addis Ababa and Gambella. They suggest some geographic differences in vulnerabilities and HIV/STI risk and highlight the need for targeted HIV prevention interventions among AGYW at highest risk. A refined understanding of the heterogeneity of HIV risk and vulnerability among AGYW can be leveraged for geospatial mapping of HIV, syphilis, and chlamydia among AGYW in Addis Ababa and Gambella and can be used to refine and prioritize areas for future HIV prevention programming in order to optimize resource allocation. 


\section{BACKGROUND AND RATIONALE}

AGYW aged 15-24 years across Southern and Eastern Africa face a disproportionately high incidence and burden of HIV compared to same-aged males and the overall adult population (Ethiopia Federal HIV/AIDS Prevention \& Control Office (FHAPCO) and Global AIDS Monitoring \& Evaluation Team (GAMET) 2008; Fleischman and Peck 2015). They experience multiple levels of vulnerabilities to HIV risk, including individual-level (e.g., biological, behavioral, and economic), interpersonal-level (e.g., gendered power dynamics, age-disparate relationships, family structure), and, ultimately, structural-level (e.g., stigma, community violence, and gender norms) (FHAPCO and GAMET 2008; Deribew 2009; Ferede and Erulkar 2009). However, the HIV-related risks among AGYW vary significantly, where being out of school presents increasing vulnerabilities including limiting the provision of social supports, counseling, and engagement in surveys and HIV testing initiatives (Zuma et al. Date unknown; Kuringe et al. 2019; Chimbindi et al. 2018).

Ethiopia has the second largest population in sub-Saharan Africa and is geographically diverse. The most recent estimates suggest that there are 794,000 people living with HIV in the country. The most recent data on population-based HIV prevalence were collected in the 2016 Ethiopia Demographic and Health Survey (DHS) (Kuringe et al. 2019). A Population HIV Impact Assessment (PHIA) was conducted in 2017-2018 (PHIA Project 2018). Nationally, the overall HIV prevalence estimated in the PHIA was 2.9 percent (95\% Cl: $2.5-3.3$ ) with $4.0 \%$ (95\% Cl: 3.5-4.6) among women aged 15-49 years and 1.7 percent (95\% Cl: 1.3-2.1) among men in the same age range (Central Statistical Agency (CSA) [Ethiopia] and ICF 2016). Prevalence in the country varies dramatically by age, sex, and location-with urban centers experiencing a much higher HIV burden. Internal migration mainly occurs from rural areas of low HIV prevalence to urban areas of high HIV prevalence, and more than half of all urban migrants are young adolescent females (Measure Evaluation Project 2005; Ezra 2001). Young female migrants are significantly more likely to reside in informal urban settlements in comparison to males their age and found to be more vulnerable than AGYW natives due to lack of social support, including parental support, and schooling (Erulkar et al. 2006). Additionally, while most migrate for economic and employment opportunities, due to lack of schooling, most employment opportunities available to AGYW migrants upon arrival are informal (Erulkar 2017; van Blerk 2008; De Regt 2016).

AGYW who are out of school may face a particular set of vulnerabilities given their limited engagement in general school-based services, e.g., counseling and linkage to care and other social support services, and may also be more likely to engage in compensated sex when there are limited other economic opportunities. In Ethiopia, the percentage of children aged 15-18 years in secondary school nationally was 18 percent in 2016 (CSA and ICF 2016). The 2016 DHS found that secondary schooling status increased with increasing household wealth. School attendance rate rapidly declined from age 15-24 years, with an estimated 70 percent of 16-year-old females and 40 percent of 18-year-old females attending school (CSA and ICF 2016). Attendance rates were higher among males than females (CSA and ICF 2016). Moreover, 
a national survey among female sex workers (FSWs) in transport corridors from different regions in Ethiopia has shown a high HIV prevalence (6\%-32\%) (UNAIDS 2016), yet there remain limited HIV prevalence data among AGYW that do not self-identify as FSWs but who may experience heightened vulnerability to HIV risk. Data from antenatal clinic surveillance among sexually active women suggest that among AGYW aged 15-24 years, 2 percent are living with HIV. Outside of the PHIA results (estimating HIV prevalence nationally among AGYW overall at $0.9 \%$ ), the only large study to our knowledge among out-of-school AGYW was a household survey of 1,836 out-of-school girls almost a decade ago. HIV prevalence data were not assessed but behavioral data suggested a heightened vulnerability to HIV (Ferede and Erulkar 2009).

Consequently, there is a need to specifically characterize the burden of HIV and specific vulnerabilities among AGYW to inform HIV prevention programming within the country. Using a venue-based approach to reach AGYW at greater risk for marginalization, the goal of this study was to focus on out-of-school AGYW rather than those who specifically self-identify as sex workers. The broader focus was warranted in order to identify AGYW who may be on a transitional pathway toward heightened risk and assess characteristics of these AGYW. Understanding AGYW on a transitional risk path is important in order to intervene before their risk is further escalated.

AHRI and Johns Hopkins Bloomberg School of Public Health through Project SOAR conducted an integrated HIV biobehavioral survey (IBBS) focused on out-of-school AGYW aged 15-24 years to assess AGYW HIV risk vulnerability. Prior to conducting the IBBS, formative work mapped potential recruitment locations and determined the best methods to recruit out-of-school AGYW in the local context. In addition, stakeholders were engaged, including the Ministry of Health $(\mathrm{MoH})$, the FHAPCO, and local health authorities within cities.

The proposed work was planned for three urban areas with elevated HIV prevalence: Addis Ababa in the center of the country, Bahir Dar in the northwest, and Gambella in the southwest. These sites were deemed priority locations by the USAID Mission and the Ethiopian $\mathrm{MoH}$ given the higher HIV prevalence observed in the 2016 DHS.

\section{OBJECTIVE AND STUDY AIMS}

AGYW aged 15-24 years are an important key population that experiences a disproportionate level of new HIV infections. This population continues to sustain high incidence rates, thus preventing achievement of ambitious UNAIDS goals for an AIDS-free generation and epidemic control by 2030. Although the disparity in HIV prevalence among young women and their male counterparts is not new, there is increasing recognition that this disparity contributes in important ways to the epidemic and must be addressed in high HIV burden countries. In Ethiopia, data characterizing unmet HIV prevention needs and HIV risk vulnerabilities among AGYW are lacking due to challenges in studying the needs of this population. Project SOAR conducted an IBBS among AGYW to characterize HIV prevalence and to estimate HIV vulnerability and risk factors in this population to guide future HIV programming. 
The objectives of the research were as follows:

1. Understand through community mapping where to find and how to recruit AGYW through key informant interviews.

2. Characterize HIV risks and vulnerabilities faced by AGYW in Ethiopia to inform future HIV prevention programming. Data collected will assess HIV risk behaviors, as well as individual, interpersonal, and structural factors creating environments of risk for AGYW.

3. Estimate the HIV prevalence of AGYW in three high HIV prevalence settings in Ethiopia.

4. Measure the burden of STIs among AGYW, including syphilis and chlamydia, and identify and map health facilities across the three settings.

This study aims to provide the Ethiopian FHAPCO and USAID/Ethiopia with HIV prevalence estimates and vulnerability assessments for predominately out-of-school AGYW at increased risk and vulnerability for HIV. These results are intended to inform future HIV prevention and treatment programming for AGYW in the country. The study also aims to provide geographic zones within urban areas where programmatic efforts should be targeted given concentration of risks among AGYW. Additionally, this study identifies current national policies and programs targeting AGYW, HIV prevention and treatment services currently being provided to AGYW in selected sites, and coverage of services and characteristics of AGYW with limited access to services.

\section{STUDY OVERVIEW}

This cross-sectional study aimed to collect data in three high HIV prevalence settings: Addis Ababa (within three sub-cities: Addis Ketema, Akaky Kaliti, and Kolfe Kerani), Bahir Dar, and Gambella. Given the lack of mapping data available for AGYW in Ethiopia, GPS mapping combined with key informant interviews were used to identify locations in which out-of-school AGYW congregate and health facility service delivery sites. In addition to the creation of a sampling frame, the mapping data allowed for exploration of geographic clustering of HIV, syphilis, and chlamydia prevalence. Participants were directly recruited at venues. Questionnaires and HIV, syphilis, and chlamydia testing were administered, and all AGYW living with HIV, syphilis, or chlamydia were linked to services for care.

As noted above, the study was planned for three high HIV prevalence settings in Ethiopia, including Addis Ababa, Gambella, and Bahir Dar. Community venue and health facility mapping and data collection activities were completed in Addis Ababa and Gambella. Community venue and health facility mapping activities were also conducted in Bahir Dar. However, the dissemination of false information by a young community activist via Facebook regarding the study purpose and procedures in Bahir Dar led to a community mob accosting the local study team on 3 August 2018, during the beginning of data collection. Although no serious injuries occurred, property damage was extensive and, after multiple rounds and levels of discussions with the study team, various stakeholders, and local authorities, it was determined that it was not safe to continue with data collection in the area and thus no further data collection activities occurred in Bahir Dar. The decision was taken with the aim of minimizing risk and maximizing safety of participants and study staff. Furthermore, based on the events that occurred in Bahir Dar, additional measures were incorporated into the research plan for community mapping and data collection activities in Gambella. 


\section{AGYW advisory board}

An advisory board consisting of 8-12 out-of-school AGYW was established in each city. The advisory board helped to identify potential venue locations, assess cultural appropriateness of the survey tool, and ensure that the voices of AGYW were incorporated into study design and implementation.

Specifically, in Gambella, an AGYW community advisory group (CAG) and a community advisory board (CAB) were selected as part of the community engagement activities. The AGYW CAG had 10 AYGW members, ranging from age 15 to 24 and representing the five kebeles of Gambella. Specifically, two AGYW per kebele in Gambella provided overall support and guidance to the data collection activities. The CAB was composed of 10 community stakeholders and officials who were selected to provide overall support the study and facilitate data collection. 


\section{COMMUNITY MAPPING}

\section{COMMUNITY MAPPING OVERVIEW}

Prior to this study, little attention was given to HIV prevention and programming efforts for AGYW in Ethiopia. This was especially the case for out-of-school AGYW but was also a broader data limitation that had been identified by the $\mathrm{MOH}$, local stakeholders, and the USAID Mission. Thus, as a precursor to study recruitment and data collection, a mapping exercise was conducted of out-of-school AGYW at each site. Steps included in the process were as follows:

\section{Identification of AGYW venues and services}

For venue identification, study staff met with key informants (KIs) until no new locations emerged with knowledge of AGYW and services for them. Based on discussions with local stakeholders, KIs were identified by their knowledge of and/or experience working with AGYW and selected based on a matrixed set of pre-determined characteristics. Based on the pre-determined characteristics, KIs included taxi drivers, truck drivers, mobile hawkers/street vendors, other migrant or mobile workers, mechanics/petrol station persons, hotel or tourism workers/managers, security guards/ cleaners, hairdresser/barbers, beer/liquor store owners, brokers, community mobilizers, peer educators/peer locators, mayor/chief/community leader, CBO/NGO staff, teachers, police/ military officer, health care workers, church workers, and urban health extension workers. Study staff asked each $\mathrm{KI}$ to list the location of services for AGYW of which they were aware and to share all venues where AGYW congregate. The total number of KIs varied by city size and density, and venues were elicited from KIs until saturation was reached. No individual level information about the $\mathrm{KI}$ or about AGYW was collected during the venue identification process; rather, KIs were asked to share their knowledge of where AGYW congregate and access services.

\section{Venue verification survey and mapping of identified sites}

The venues reported by the Kls were aggregated and grouped according to geographic distribution and type of venue. The AGYW CAG facilitated the venue aggregation process. A subsample of venues was selected for venue verification from this list with a focus on achieving diversity of AGYW in terms of age, high risk activities, and geographic representation. A subset of venues from Addis Ababa and Bahir Dar was selected for verification. The number of venues selected was based on the total number identified. If 200 or fewer venues were identified, all venues (100\%) were validated; if more than 200 were identified, a power function was utilized such that as the number of venues per sub-city increased, the total venues validated also slowly increased ( $y=61.684 \times 0.778)$. In the case of Gambella, given that the power calculation estimate approached the total number of venues listed, the team decided to complete 100 percent validation to ensure completeness. Venues mentioned five or more times by KIs were considered high priority and automatically included for validation. Of the remaining venues, venues were then randomly sampled proportional to the venue type (e.g., bars/restaurants, broker houses, 
brothels). The exception to this rule was smaller venue types (comprising less than $3 \%$ of venues); to ensure representation of smaller venue types we selected all venues from these types for validation.

Trained interviewers visited the venues to verify their existence. At the venue, an interview was performed with a person knowledgeable about the venue such as the venue owner, manager, or other employees or gatekeepers; a letter to the venue manager explained the study duration and procedures. Civilian-dressed police officers facilitated safety as needed and, in Gambella, AGYW CAB members supported entry to the venues. The venue verification survey was conducted over 30 minutes and served to locate, characterize, and assess the venue according to the type of activities that occur there, the patrons, availability of HIV prevention services, and the total number of AGYW on-site, among other characteristics. A GPS waypoint coordinate was taken at the site using EpiCollect+ application. ${ }^{1}$

\section{Venue sampling}

Once venues were identified and verified, a sampling frame of venues was constructed. Venuebased time location sampling (TLS) using 4-hour blocks was used to construct a venue sampling frame; a stratified sampling approach was used to sample from the complete eligible venue list to ensure representation of diverse types of sites (PHIA Project 2018). Venues with eight or more AGYW per hour on-site were eligible to be sampled for data collection (PHIA Project 2018). At least eight AGYW per hour ensured AGYW frequented the venue and preserved the minimum effective yield during a given sampling event to maximize productivity. Eligibility criteria for venues to be included in the final venue sampling frame were: 1) majority of AGYW attending venue were out-of-school; 2) four or more AGYW observed during a 30-minute observation period at the venue; 3) venue deemed safe by data collection team; and 4) key gatekeepers were accepting of study activities. The AGYW CAG facilitated validation, helping to locate venues, grant entry, and build rapport. To assess whether the majority of AGYW were out-of-school, the study team observed whether AGYW were wearing school uniforms (if verification activities occurred during school hours) and discussed schooling status with AGYW and venue managers present at the venue during venue verification. A random selection of venues to visit, including days and times, were chosen for data collection utilizing the sampling frame and random sampling without replacement.

\section{Health service assessment and mapping of identified sites}

In parallel with the AGYW venue mapping processes, all major public and private health service facilities were visited, and a health service delivery assessment was administered to the person identified as leading the site. These participants were asked about the type of services, funding and management of services, the type of patients served, staffing, and HIV prevention, testing, care, and treatment services available. For programmatic mapping purposes, similar to mapping venues, a GPS waypoint coordinate was also collected using EpiCollect+ GPS application. This mapping exercise was also used to identify sites and develop relationships with clinics in order to put into place strong referral mechanisms for AGYW who tested HIV-positive during the study or were found to be in need of syphilis or chlamydia treatment.

${ }^{1}$ http://www.epicollect.net/ 


\section{COMMUNITY MAPPING RESULTS}

\section{Addis Ababa}

In Addis Ababa, of the 2,486 unique venues identified through $688 \mathrm{KI}$ discussions, 802 were selected for verification and, of these, 371 were determined eligible for sampling. Figure 1 outlines the mapping process in Addis Ababa. Of the 371 eligible venues, 81 were randomly sampled for data collection. A total of 33 health facilities were identified and mapped in Addis Ababa. The majority, 88 percent, were governmental hospitals/clinics. Figure 2 maps the eligible and sampled venues and health facilities across the three sub-cities by geolocation.

Additional information documenting AGYW-friendly health services and operating hours is detailed in Appendix 1 for all three sites.

Figure 1 Venue mapping in Addis Ababa

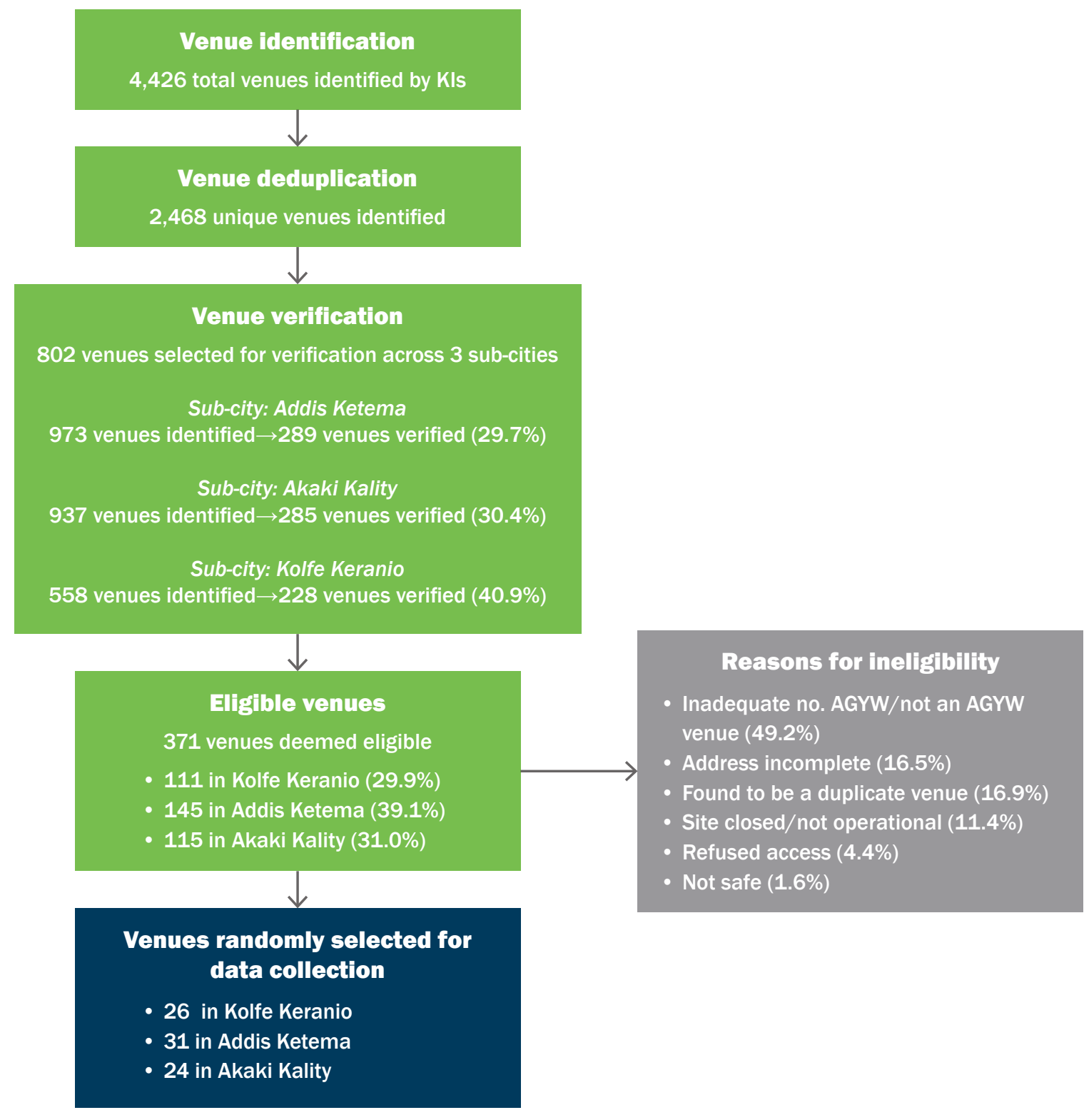


Figure 2 Mapping of validated and selected venues and health facilities in three sub-cities of Addis Ababa

Maps illustrate (a) health facilities and eligible and selected venues across the three sub-cities and (b) distribution of health facilities and selected venues bv venue tvpe.

(a)

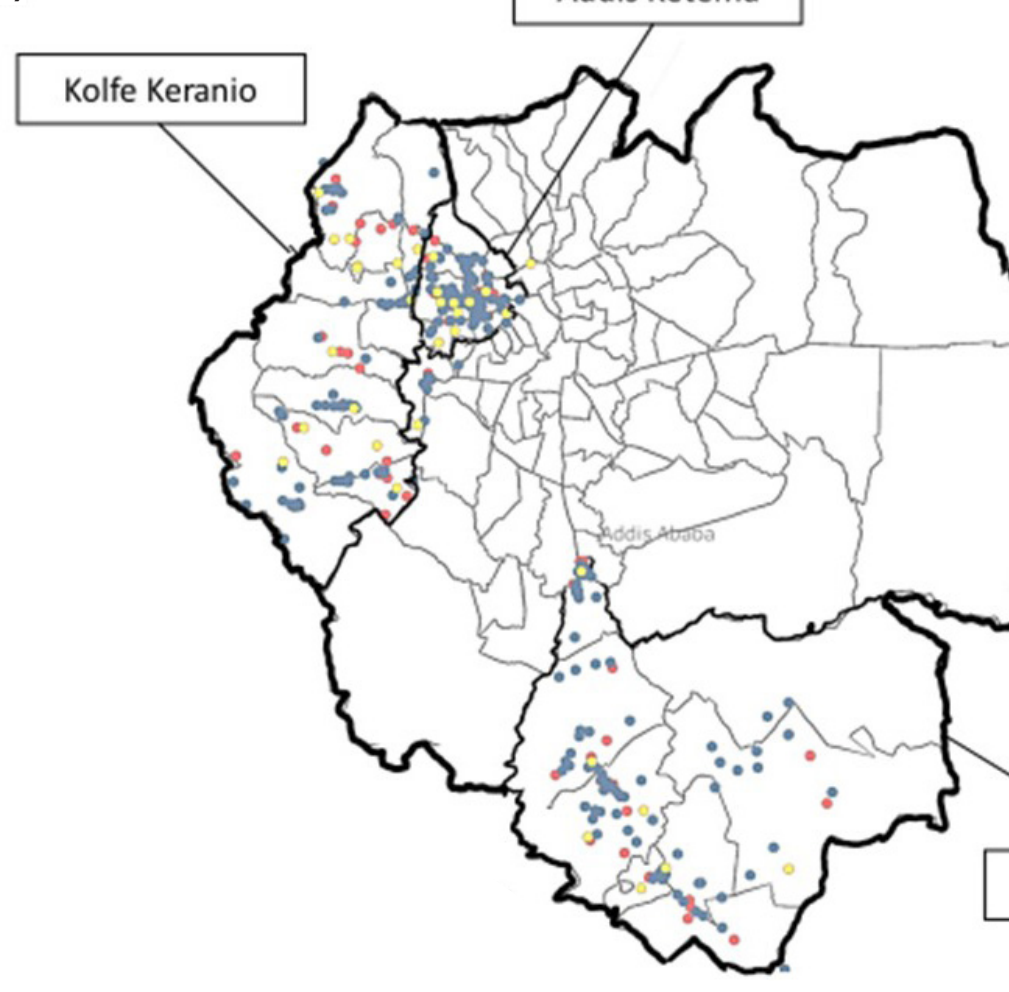

\section{Type of venue or facility}

Facilities

Eligible venues

Eligible venues selected for data collection (b)

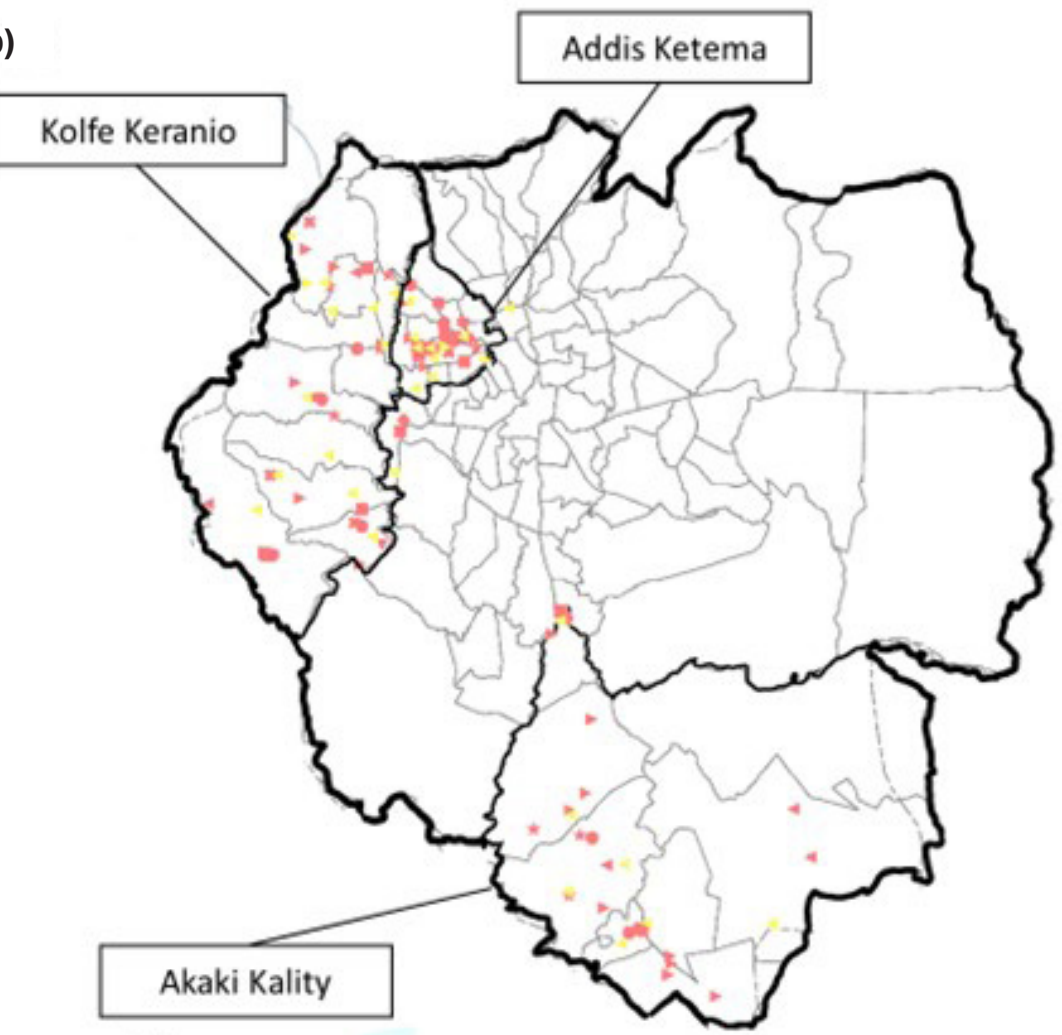

Type of venue or facility

1-Bar, restaurant

2-Hotel, hostel, guest house

+3-Brothel

* 4-Broker's place

5-Street, street corner, street market

6-Public space, park, lake shore

- 7-Khat bar, shisha bar

$\checkmark$ 8-Night club, strip club

9-Construction site

10-Shed, factories

12-Cinema, video shops

14-Main transportation center

15-Special villages (e.g., Alga Bet)

* 16-Youth center

17-Training center

-18-Beauty salon

$\nabla$ 19-Other

4 Governmental hospital, clinic

$>$ NGO, CBO

\section{Site type}

Facility

Venue

${ }^{\wedge}$ Maps present data collected exclusively in Addis Ketema, Akaki Kality, and Kolfe Keranio. 


\section{Bahir Dar}

In Bahir Dar, of the 856 unique venues identified through $221 \mathrm{KI}$ discussions, 277 (32\%) were selected for verification and, of these, 177 (63\%) were determined eligible. Figure 3 outlines the mapping process in Bahir Dar. Of the 177 eligible venues, 37 were randomly sampled for data collection. A total of six health facilities were identified and mapped in Bahir Dar and all were governmental hospitals/clinics. Figure 4 maps the eligible and sampled venues and health facilities across the city by geolocation.

Figure 3 Venue mapping in Bahir Dar

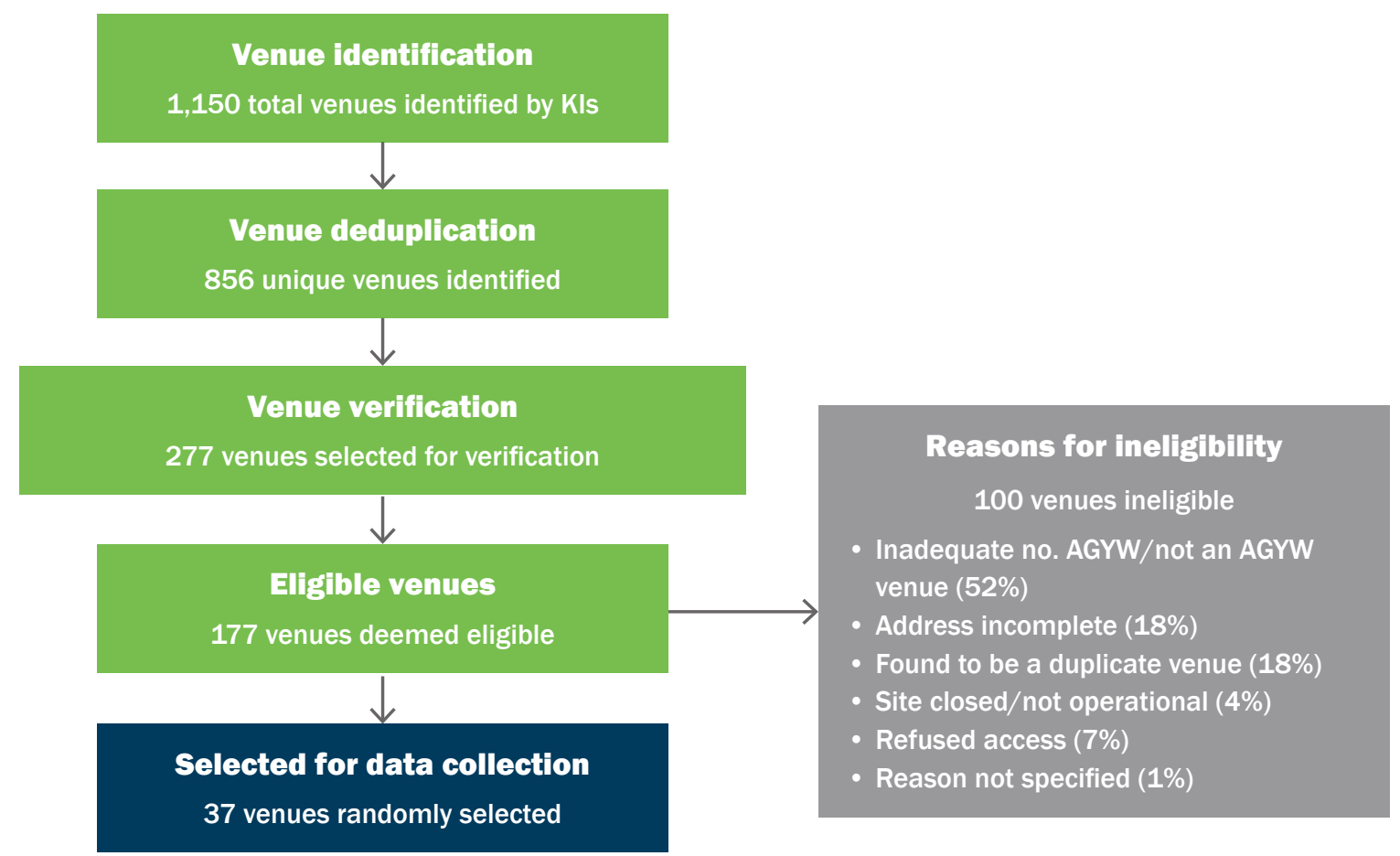


Figure 4 Mapping of validated and selected venues and health facilities in Bahir Dar

Maps illustrate (a) health facilities and eligible and selected venues (b) distribution of health facilities and selected venues by venue type

(a)
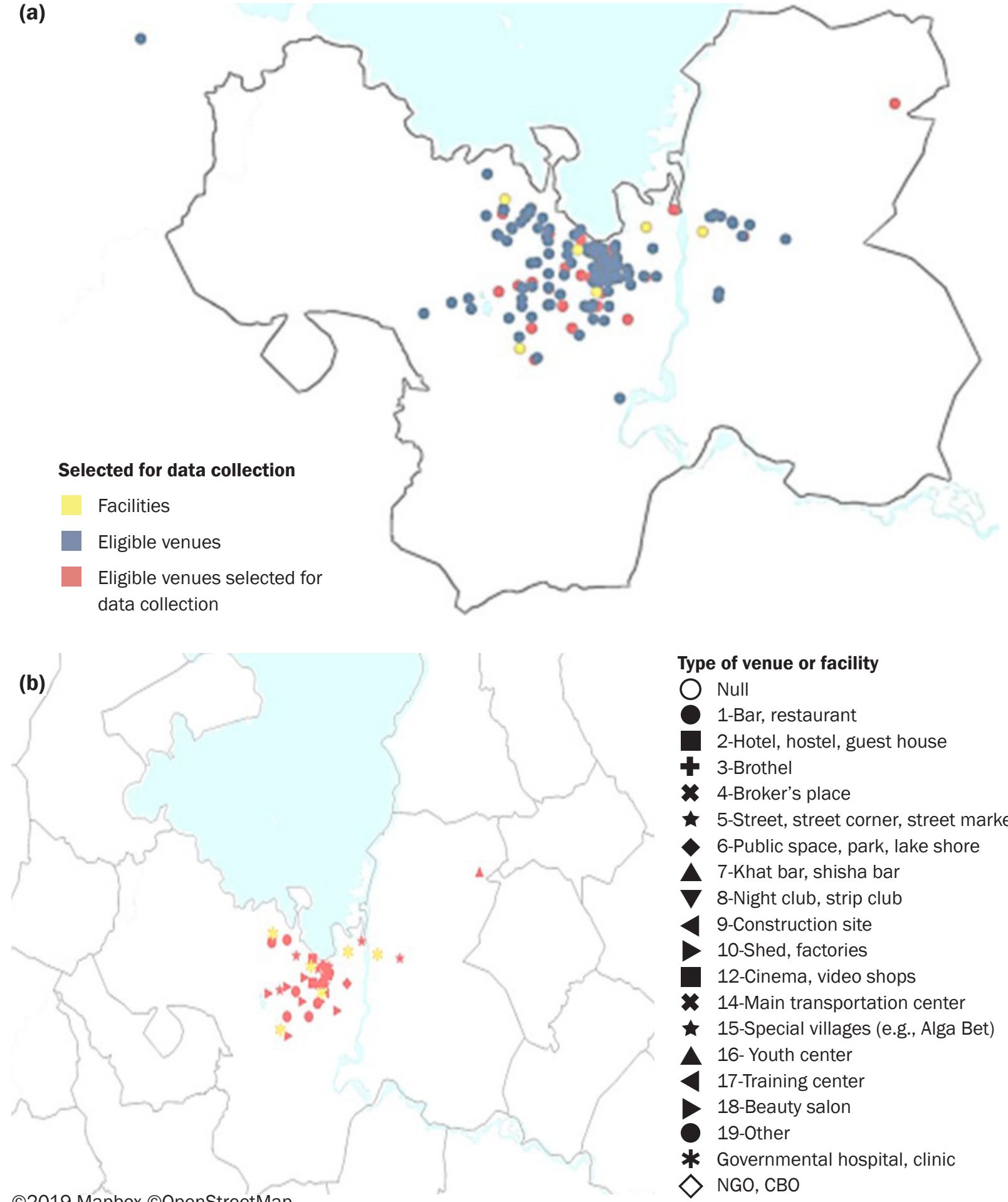

(C)2019 Mapbox (C) OpenStreetMap

Type of venue or facility

Null

1-Bar, restaurant

2-Hotel, hostel, guest house

1 3-Brothel

* 4-Broker's place

5-Street, street corner, street market

6-Public space, park, lake shore

- 7-Khat bar, shisha bar

$\checkmark$ 8-Night club, strip club

4 9-Construction site

10-Shed, factories

12-Cinema, video shops

* 14-Main transportation center

$\star$ 15-Special villages (e.g., Alga Bet)

116- Youth center

1 17-Training center

18-Beauty salon

19-Other

* Governmental hospital, clinic

$\diamond \mathrm{NGO}, \mathrm{CBO}$

Map based on Longitude (generated) and Latitude (generated). For pane Longitude (generated) (2): Color shows details about those selected for data collection ${ }^{\dagger}$, which keeps facilities and eligible venues selected for data collection.

\section{Selected for data collection ${ }^{\dagger}$}

Facilities

Eligible venues selected for data collection 


\section{Gambella}

In Gambella, there were 306 unique venues identified through $108 \mathrm{KI}$ discussions, all 306 (100\%) were selected for verification and, of these, $211(68 \%)$ were determined to be eligible.

Figure 5 outlines the mapping process in Gambella. Of the 211 eligible venues, 44 were randomly sampled for data collection. A total of six health facilities were mapped in Gambella to date. Figure 6 maps the eligible and sampled venues and health facilities by geolocation.

Figure 5 Venue mapping in Gambella

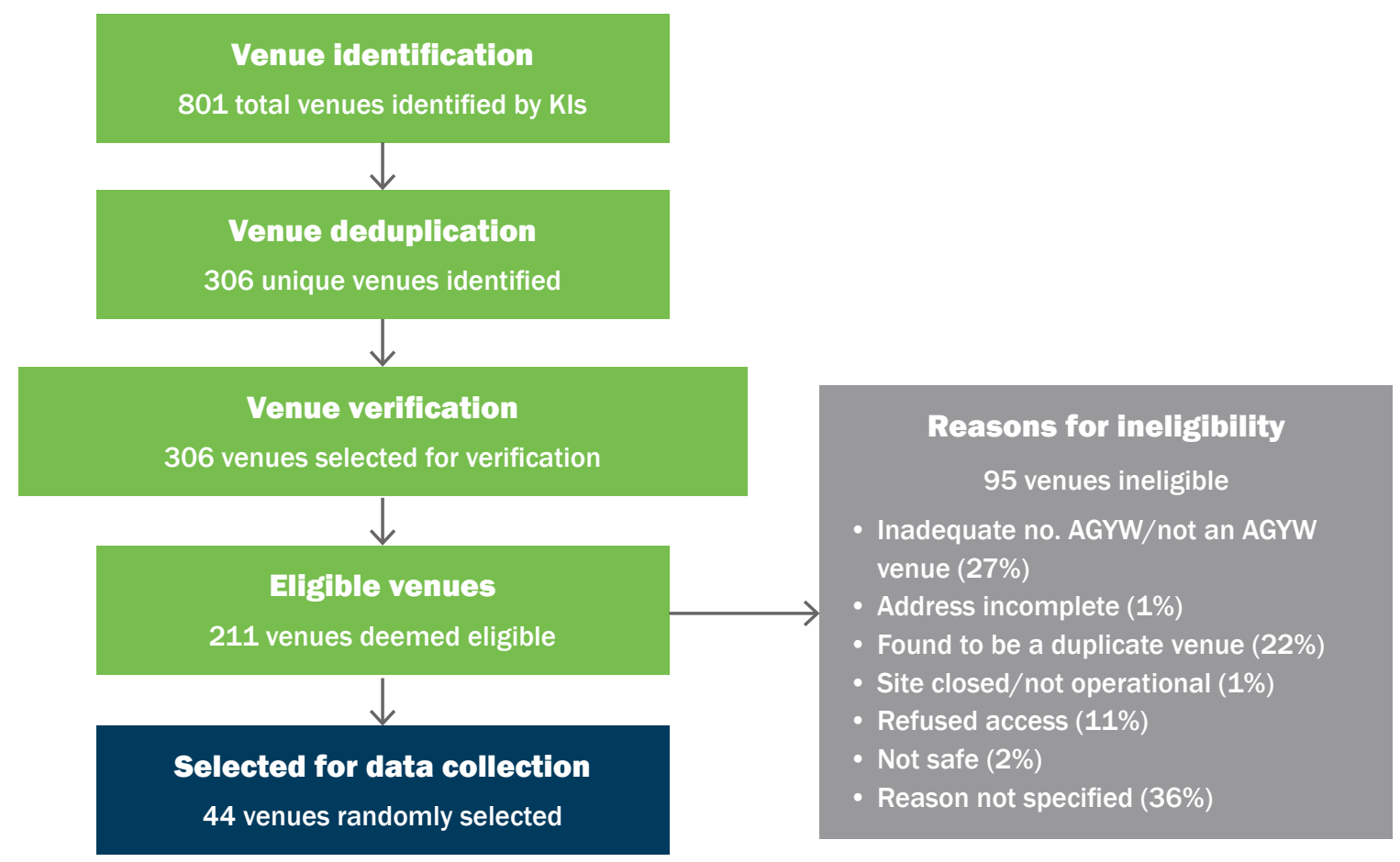


Figure 6. Mapping of validated and selected venues and health facilities in Gambella Maps illustrate (a) health facilities and eligible and selected venues (b) distribution of health facilities and selected venues by venue type

(a)

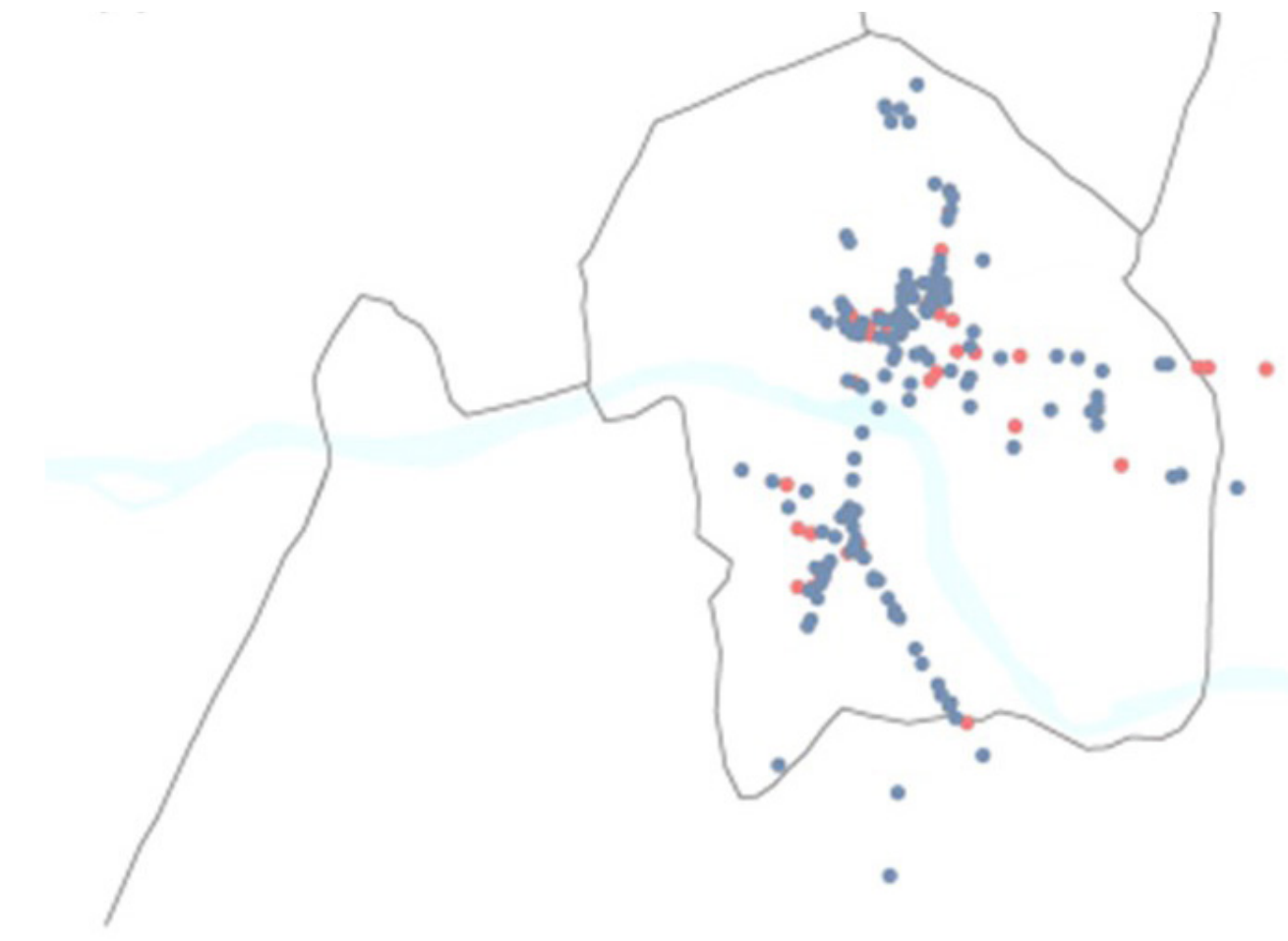

Selected for data collection

Facilities

Eligible venues

Eligible venues selected for data collection 
(b)

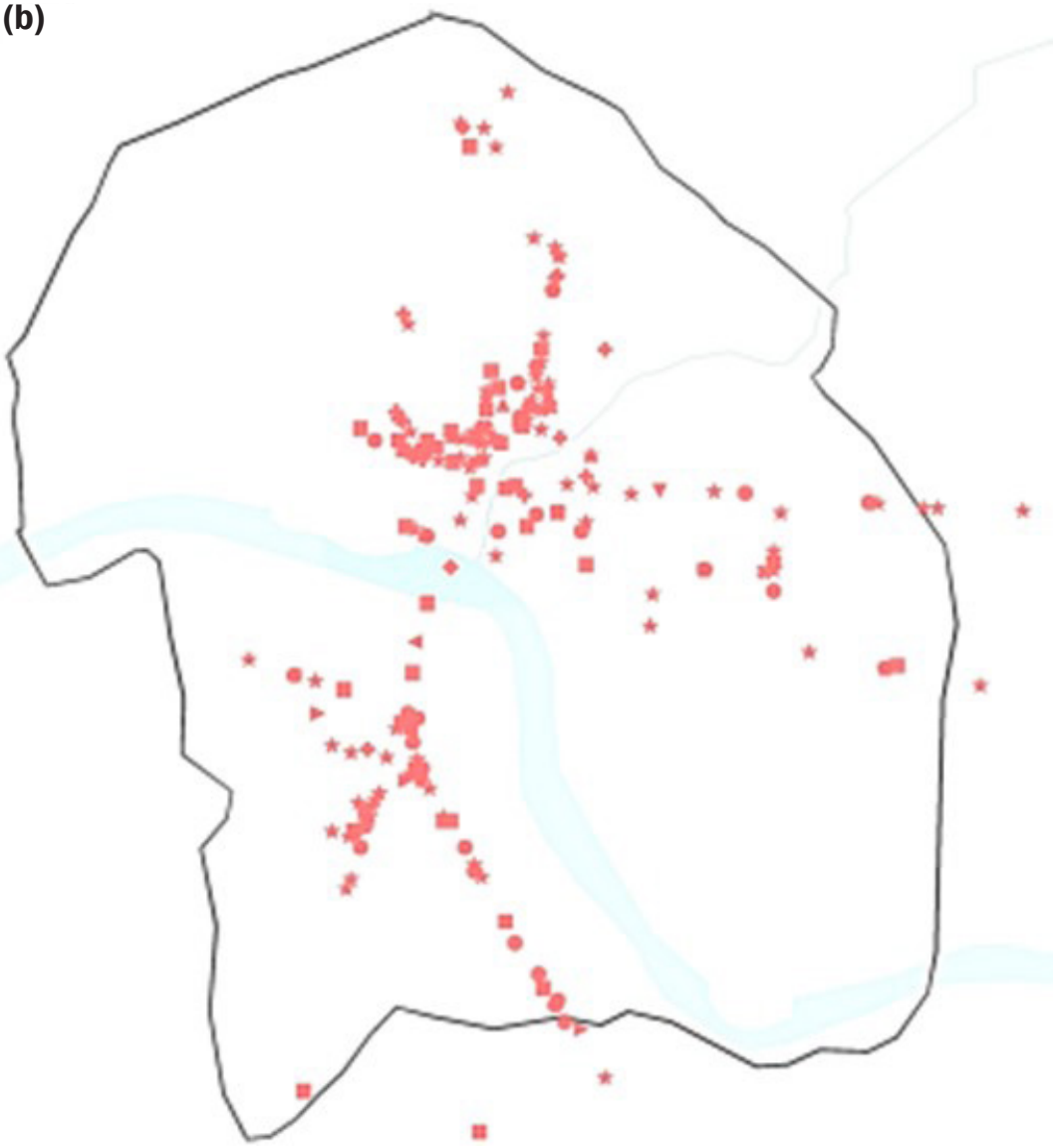

Type of venue or facility

1-Bar, restaurant

2-Hotel, hostel, guest house

+3-Brothel

* 4-Broker's place

- 5-Street, street corner, street market

6-Public space, park, lake shore

7-Khat bar, shisha bar

$\nabla$ 8-Night club, strip club

4 9-Construction site

10-Shed, factories

- 11-Massage center

12-Cinema, video shops

+ 13-Church compound

* 14-Main transportation center

$\star$ 15-Special villages (e.g., Alga Bet)

16-Youth center

4 17-Training center

18-Beauty salon

19-Other

\section{Selected for data collection}

Venue 


\section{INTEGRATED HIV BIOBEHAVIORAL SURVEY}

\section{OVERVIEW}

Data collection lasted 60-90 minutes, including informed consent, the questionnaire, and biological testing for HIV, syphilis, and chlamydia. Administration of the questionnaire and biological specimen collection were conducted by qualified nurses who had completed detailed training in the study procedures as well as human research ethics training. AGYW received reimbursement for their time at a level in line with local research reimbursement standards. Specifically, in Addis Ababa and Bahir Dar, 300 Birr (US\$13.04) was provided as reimbursement. In Gambella, participants received 200 Birr (US\$ 8.70) as reimbursement. Ethical review was sought and received from the AHRI, the National Research Ethics Committee, and the institutional review board at Johns Hopkins Bloomberg School of Public Health.

\section{METHODS}

\section{Recruitment procedures}

As noted above in the community mapping section, TLS was used to determine days and times that each of the verified venues had high levels of congregation of AGYW. Sampling followed standard TLS methods used in several settings and was based on the Priorities for Local AIDS Control Efforts (PLACE) (Measure Evaluation Project 2005). The PLACE method is a strategy used to systematically identify where to reach individuals at highest risk for acquiring and transmitting HIV and where service delivery locations are operating, with the aim of developing evidencebased plans and strategies to address gaps. Specifically, AGYW were systematically approached and recruited at the venues during study visits. Study enrollment included both day and early evening hours.

Three sub-cities of Addis Ababa-Addis Ketema, Akaky Kaliti, and Kolfe Keranio-were purposively selected based on venue type and geographic diversity. In Bahir Dar and Gambella, the entire cities were eligible for participation. To complete the TLS, community mapping ensued (as outlined in the Community Mapping section). All AGYW at the selected venue on the selected day and time block were systematically informed of the study, screened for eligibility, and offered participation in the study if eligible (i.e., a take-all approach until total desired sample size or 4-hour sampling block timeframe was completed). In Addis Ababa, a maximum of 15 AGYW per venue were recruited to ensure that one venue did not overpopulate the sample. In Gambella, a maximum of 21 AGYW per venue were recruited, as venue yield was high and additional data collectors were available. Within Gambella, regional tensions made data collection at night unsafe and thus some time blocks that would have otherwise been eligible were excluded. 
Following events in Bahir Dar, additional security measures were taken during data collection in Gambella. Thus, in Gambella, venue managers were provided with tailored official letters to inform them of the study process and target population, and duration of data collection. A local kebele officer supported recruitment and data collection activities at AGYW venues in their respective kebele. The team ensured that the study's relationship with the venue managers was solely focused on obtaining entry into the site and protecting the participants' confidentiality. A banner hung at the venue informed the community that this is a "young woman's health study" to legitimize study activities, and a civilian-dressed police officer was present around the venue during data collection activities to ensure safety of the participants and study staff. Members of the AGYW community advisory group were available to provide input and support entry into the venues, as needed.

Prior to enrollment and commencement of study procedures, all participants provided written informed consent.

\section{Sample size}

The sample size calculation was determined based on prevalence estimates from ANC and DHS data in the targeted cities. Specifically, HIV prevalence was anticipated to be around 5 percent among out-of-school AGYW, which is approximately twice as high as that among all sexually active age-matched AGYW with aforementioned data from ANC. It was also estimated that 80 percent of the AGYW sampled in these venues were out-of-school. Thus, in order to estimate HIV prevalence with a hypothesized prevalence of 5 percent and a precision of $+/-1.5$ percent, the aim was to enroll 1,500 AGYW, with the following enrollment per city: Addis Ababa $(n=800)$ and Gambella $(n=700)$. Estimates varied by site based on the estimated population size of the city, with population estimates used from national census data. ${ }^{2}$ It was assumed that 20 percent of the population is aged 15-24 years, per the country's demographic composition, half of which were females, with an estimated 10 percent of those out-of-school AGYW at greater risk for HIV.

\section{Inclusion criteria}

This study targeted out-of-school AGYW. However, being out-of-school was not an explicit inclusion criterion, though the mapping process and key informants were focused on providing information on sites where out-of-school youth concentrate. Study inclusion and exclusion criteria are outlined in Table 1.

\section{Table 1 AGYW inclusion and exclusion criteria}

\begin{tabular}{|ll|}
\hline Inclusion criteria & Exclusion criteria \\
- AGYW aged 15-24 years living in the cities of Addis Ababa and Gambella & $\begin{array}{l}\text { Tourists or individuals that } \\
\text { - Able to provide informed consent (aged 18-24 years) }\end{array}$ \\
$\begin{array}{l}\text { - Able to provide informed consent with emancipated minor status using } \\
\text { rules and regulations established by Ethiopian Research Guidelines to } \\
\text { achieve consent for those aged 15-17 years }\end{array}$ & \\
\hline
\end{tabular}

\footnotetext{
${ }^{2}$ https://www.census.gov/programs-surveys/international-programs/about/idb.html
} 
Although the study was targeting out-of-school AGYW, in order to avoid stigmatizing this group, AGYW enrolled in school at the enrollment sites were also eligible to participate. In order to ensure that our sample primarily consisted of out-of-school AGYW, the community mapping only including venues in the sampling frame in which the majority of the AGYW on site were out-of-school AGYW.

\section{Data collection}

\section{Survey questionnaires}

After providing informed consent, AGYW participants completed an interviewer-administered face-to-face structured survey that lasted approximately 45 minutes and was conducted in a private setting to ensure safety and confidentiality of participants. Participants were first asked about sociodemographic information, followed by an AGYW HIV vulnerability assessment recently developed in partnership with the DREAMS program in Tanzania (CSA and ICF 2016), as well as questions focused on stigma, human rights violations including violence, reproductive health, and health service access. For venues in which a private space was not available, interviews were conducted in study tents or in the study vehicle. Interviews were conducted in Amharic, English, or Nuer depending on the setting.

\section{Biological testing}

All biological samples were collected by a trained technician, stored, and disposed of according to the national laboratory standards of Ethiopia. Collection took place in the community with consenting participants in addition to the administration of the questionnaire. Pre- and posttest counseling was included with HIV, syphilis, and chlamydia testing and followed national standards. According to national Ethiopian guidelines, all study participants provided five $\mathrm{mL}$ of whole blood for HIV, syphilis, and chlamydia testing with pre- and post-test counseling completed (CSA and ICF 2016). The test kits utilized Addis Ababa and Gambella for the sequential HIV testing algorithm included Beijing I, Uni-Gold, and VIKIA (tie-breaker) and STAT-PAK, ABON BIOPHARM, and SD BIOLINE (tie-breaker), respectively. The HIV test kits changed due to a change in the national guidelines. Syphilis and chlamydia testing were conducted using the Healgen Rapid Lateral Flow Test and EUROIMMUN assays, respectively. HIV, syphilis, and chlamydia testing were linked to informed consent and pre-test and post-test counseling, and kept, without personal identifiers or names, in a study database.

AGYW who tested positive for HIV and who did not indicate a prior diagnosis or who were not linked into care were provided with referrals to care. Results were attached to the referral letter for linkage to care as per the national standard of practice. In Gambella, the nurse interviewer also conducted STI syndromic screening, per the national guidelines, for all participants. Participants identified with STI symptoms were provided a referral letter to the local clinic in Gambella for treatment.

For syphilis and chlamydia testing, blood samples were transferred to a local regional governmental organization for processing. Specifically, processing occurred locally in Addis Ababa and Gambella at AHRI and Gambella Regional Laboratory, respectively. In Gambella, syphilis testing occurred at the Gambella Regional Laboratory, as noted. Chlamydia testing occurred at AHRI, in Addis Ababa. Blood samples were transported from Gambella to Addis Ababa via the Ethiopian Postal Service, which uses Ethiopia Airlines. 
Participants with a cell phone received an automatic text message 14 to 21 days after the blood draw from the study staff stating, "Your results are ready. You may call at any time or place a free "Please Call Me" text which will be returned with a call from study staff as soon as possible." The free "Please Call Me" option was available for participants who did not have credit on their phone or did not want to place the call themselves. During the phone call, the staff spoke only to the participant and did not leave a voice message or a message with another person. In a number of instances, the staff called back another time. During the phone call with participants, study staff first established that they were talking with the correct participant and that the participant was in a safe space to talk. In order to identify that the participant was correct, the unique participant ID was verbally requested over the phone. Data collectors also provided participants with a calling card with a study-specific phone number, and participants were informed that they could call the number directly to receive their STI results. Participants without a personal phone were contacted in-person or could call the study team directly to obtain their results and post-test counseling. Participants who did not wish to be texted by study staff or did not personally own a cell phone were able to call a phone number provided on a calling card with a phone number where post-test counseling and the syphilis and chlamydia test results were provided. Participants were referred to a local health facility if their results were positive. Additionally, for all syphilis and chlamydia tests, if results were available in fewer than 14 days, a text message asking the participant to call for results was sent as soon as the results were available.

\section{RESULTS}

\section{Overview of data collection}

Participant enrollment in Addis Ababa began on 21 February 2018 and ended on 11 June 2018. A total of 1,882 AGYW were screened, of which 800 (42\%) AGYW were eligible and enrolled from the 81 randomly sampled venue-day-time blocks across the three sub-cities-337 in Addis Ketema, 281 in Akaki Kality, and 182 were enrolled in Kolfe. A quarter $(n=467)$ of AGYW screened in Addis Ababa were ineligible, and among those eligible, 615 (33\%) refused.

The study team arrived in Bahir Dar on 24 June 2019 and proceeded with health facility mapping and venue mapping of venues attended by AGYW as outlined in the research plan. AGYW venue mapping and verification was completed 21 July 2018 and the sampling frame was developed 23-30 July 2018. Data collection activities began on 2 August 2018. Prior to the commencement of any research activities in Bahir Dar, substantial engagement with the community took place. On 3 August 2018, the unanticipated event previously described occurred. After this event, all data collection activities were stopped in Bahir Dar and the team returned to Addis Ababa. A total of 10 AGYW were enrolled from Bahir Dar, but due to the small sample size from Bahir Dar, these data are not reported within this report.

After the event in Bahir Dar, substantial effort was made to maximize safety and minimize risk in planning to move forward with data collection activities in Gambella. Specifically, the JHUAHRI team explored different strategies for community engagement on social media platforms and created a study-related Facebook page as an additional avenue of community engagement. Additionally, a letter outlining the study aims, rationale, target population, timeline, and output 
was circulated within the city and to all relevant stakeholders, and stakeholder organizations (i.e., the police commissioner as well as all subordinates). A city-wide community engagement meeting occurred in Gambella on 11 January 2019. The community engagement activity included youth activities, volunteers, Kebele admin, health facility officers, police officers, local media, AGYW advisor board members, community representatives, and others working on HIV-related activities (Red Cross and NGO staff, laboratory officials, and technicians) who were jointly identified by the AHRI research team and local facilitators. The in-person meeting briefed attendees about the study objectives and importance, and clearly communicated that the study had been ethically approved by the AHRI ethical review board, the Ethiopian national ethical review board, and the Johns Hopkins Bloomberg School of Public Health ethical review board. The community engagement activities offered the opportunity for the community to provide constructive feedback on the study design and safety procedures.

A protocol and ethics training was conducted with Addis-based and Gambella-based data collectors at AHRI from 14 to 25 April 2019 prior to data collection in Gambella. The data collection team in Gambella was composed of local employees in addition to the Addis Abababased personnel who had administered prior data collection. The CAG and CAB met again prior to the study re-launch and supported monitoring of study implementation, as well as the community's response to implementation. The study team met daily to discuss implementation and ensure successful completion of activities and overall objectives. Daily debriefs included input from the supervisor, local facilitators, AGYW advisory board, and civilian-dressed police officer, if necessary.

Following mapping and enumeration exercises, data collection commenced in Gambella on 12 June 2019. Data collection activities were completed in Gambella on 9 July 2019. In Gambella, out of the total 1,262 young women screened, 701 women consented and enrolled into the study. Of the remaining 561 women screened, 64 declined engagement with the study team (12\%), 243 were not eligible (43\%), 57 had a language barrier (10\%), and 197 were eligible but refused participation (35\%).

\section{Demographic characteristics}

Of the 1,501 AGYW enrolled, 53 percent were from Addis Ababa and 47 percent were from Gambella. Of the AGYW enrolled from Addis Ababa, the distribution across Addis Ketema, Akaki Kaliti, and Kolfe Keranio was roughly proportionate to the size of the sub-city, with a distribution of 42 percent, 35 percent, and 23 percent, respectively. The mean age of AGYW enrolled was 19.9 years ( $\mathrm{sd} \pm 2.5$ ), and 64 percent were out-of-school. Among 15- to 19-year-old AGYW, 54 percent were out-of-school. Slightly less than two-thirds of AGYW enrolled had migrated into the city: 70 percent of participants from Addis Ababa had migrated into the city and 53 percent of participants from Gambella reported migrating into the city. The demographic characteristics of enrolled AGYW overall and by city are presented in Table 2.

The average ages of AGYW enrolled in Addis Ababa was higher ( $p$ value $=0.001$ ). There were notable differences across settings beyond ethnic differences ( $p$ value $=0.000$ ). Income and migration were both lower in Gambella ( $p$ value $=0.000$ and $p$ value $=0.000$, respectively), while educational attainment and school attendance were higher in Gambella ( $p$ value $=0.000$ and $p$ value $=0.000$, respectively). Employment was higher in Addis Ababa ( $p$ value $=0.000$ ). 


\begin{tabular}{|c|c|c|c|c|c|c|}
\hline \multirow{5}{*}{$\begin{array}{l}\text { Age in years } \\
\text { Weekly income (ETB) }\end{array}$} & \multirow{2}{*}{\multicolumn{2}{|c|}{$\begin{array}{c}\text { Total } \\
(n=1,501) \\
\text { Mean (SD) }\end{array}$}} & \multirow{2}{*}{\multicolumn{2}{|c|}{$\begin{array}{l}\text { Addis Ababa } \\
\qquad(n=800) \\
\text { Mean (SD) }\end{array}$}} & \multirow{2}{*}{\multicolumn{2}{|c|}{$\begin{array}{c}\text { Gambella } \\
(n=701) \\
\text { Mean (SD) }\end{array}$}} \\
\hline & & & & & & \\
\hline & \multicolumn{2}{|c|}{$19.9( \pm 2.5)$} & \multicolumn{2}{|c|}{$20.1( \pm 2.5)$} & \multicolumn{2}{|c|}{$19.7( \pm 2.4)$} \\
\hline & \multicolumn{2}{|c|}{$395( \pm 583)$} & \multicolumn{2}{|c|}{$474( \pm 683)$} & \multicolumn{2}{|c|}{$306( \pm 426)$} \\
\hline & $\mathrm{n}$ & $\%$ & $n$ & $\%$ & $n$ & $\%$ \\
\hline \multicolumn{7}{|l|}{ Age $^{*}$} \\
\hline $15-19$ years & 690 & 46.0 & 334 & 41.8 & 356 & 50.9 \\
\hline $20-24$ years & 809 & 54.0 & 466 & 58.2 & 343 & 49.1 \\
\hline \multicolumn{7}{|l|}{ Duration of time in city ${ }^{\dagger}$} \\
\hline$<1$ year & 151 & 10.1 & 102 & 12.7 & 49 & 7.0 \\
\hline $1-5$ years & 564 & 37.6 & 303 & 37.9 & 261 & 37.3 \\
\hline$>5$ years & 219 & 14.6 & 160 & 20.0 & 59 & 8.4 \\
\hline Always & 566 & 37.7 & 235 & 29.4 & 331 & 47.3 \\
\hline \multicolumn{7}{|l|}{ Origin of migration } \\
\hline City & 184 & 19.7 & 100 & 17.7 & 84 & 22.7 \\
\hline Town & 270 & 28.8 & 161 & 28.4 & 109 & 29.5 \\
\hline Rural area & 482 & 51.5 & 305 & 53.9 & 177 & 47.8 \\
\hline \multicolumn{7}{|l|}{ Accompanied migration } \\
\hline Alone & 234 & 25.0 & 139 & 24.6 & 95 & 25.7 \\
\hline Parent(s) & 80 & 8.6 & 56 & 9.9 & 24 & 6.5 \\
\hline Husband, boyfriend, or partner & 44 & 4.7 & 17 & 3.0 & 27 & 7.3 \\
\hline Brother, sister, or other family & 409 & 43.7 & 269 & 47.6 & 140 & 37.8 \\
\hline Friend & 156 & 16.7 & 78 & 13.8 & 78 & 21.1 \\
\hline Other & 12 & 1.3 & 6 & 1.1 & 6 & 1.6 \\
\hline \multicolumn{7}{|l|}{ Reason for migration (>1 response possible) } \\
\hline Make money & 555 & 59.5 & 398 & 70.7 & 157 & 42.4 \\
\hline Education or training & 388 & 41.5 & 185 & 32.8 & 203 & 54.9 \\
\hline Escape armed conflict & 5 & 0.5 & 2 & 0.4 & 3 & 0.8 \\
\hline Escape natural disaster & 4 & 0.4 & 2 & 0.4 & 2 & 0.4 \\
\hline For marriage or to find a partner & 24 & 2.6 & 10 & 1.8 & 14 & 3.8 \\
\hline Sell sex & 21 & 2.3 & 8 & 1.4 & 13 & 3.5 \\
\hline Other reason & 67 & 7.3 & 53 & 9.4 & 14 & 3.9 \\
\hline \multicolumn{7}{|l|}{ Religion $^{\dagger}$} \\
\hline Orthodox & 897 & 59.8 & 599 & 75.0 & 298 & 42.5 \\
\hline Protestant & 443 & 29.5 & 110 & 13.8 & 333 & 47.5 \\
\hline Muslim & 139 & 9.3 & 88 & 11.0 & 51 & 7.3 \\
\hline Other & 21 & 1.4 & 2 & 0.2 & 19 & 2.7 \\
\hline \multicolumn{7}{|l|}{ Ethnic group } \\
\hline Amhara & 399 & 26.6 & 303 & 37.9 & 96 & 13.7 \\
\hline Guragie & 148 & 9.9 & 139 & 17.4 & 9 & 1.3 \\
\hline Oromo & 451 & 30.1 & 213 & 26.6 & 238 & 33.9 \\
\hline Tigray & 75 & 5.0 & 43 & 5.4 & 32 & 4.6 \\
\hline Welaita & 79 & 5.2 & 51 & 6.4 & 28 & 4.0 \\
\hline Anuwak & 114 & 7.6 & - & - & 114 & 16.3 \\
\hline Hadiya & 65 & 4.3 & 15 & 1.9 & 50 & 7.1 \\
\hline Other & 170 & 11.3 & 36 & 4.4 & 134 & 19.1 \\
\hline $\begin{array}{l}\text { Ever attended school } \\
\text { Highest level of school attended }\end{array}$ & 1,433 & 95.5 & 755 & 94.4 & 678 & 96.7 \\
\hline Primary 1 cycle (grades $1-4$ ) & 127 & 8.9 & 100 & 13.3 & 27 & 4.0 \\
\hline Primary 2 cycle (grades $5-8$ ) & 526 & 36.7 & 302 & 40.0 & 224 & 33.0 \\
\hline Secondary $(9-10) /$ preparatory $(11-12) /$ technical & 467 & 32.6 & 233 & 30.9 & 234 & 34.5 \\
\hline College/university & 312 & 21.8 & 119 & 15.8 & 193 & 28.5 \\
\hline Currently enrolled in school ${ }^{\ddagger}$ & 543 & 36.4 & 195 & 24.7 & 348 & 49.8 \\
\hline
\end{tabular}




\begin{tabular}{|c|c|c|c|c|c|c|}
\hline Able to read ${ }^{\dagger}$ & 1,246 & 83.0 & 700 & 87.6 & 540 & 77.0 \\
\hline Own a mobile phone ${ }^{\S}$ & 1,297 & 86.4 & 691 & 86.6 & 606 & 86.5 \\
\hline Use mobile for mobile banking" & 92 & 6.1 & 26 & 3.3 & 66 & 9.4 \\
\hline Own a bank account ${ }^{\dagger}$ & 850 & 56.6 & 463 & 57.9 & 347 & 55.2 \\
\hline Use internet $^{*}$ & 462 & 30.8 & 263 & 32.9 & 199 & 28.4 \\
\hline \multicolumn{7}{|l|}{ Employment } \\
\hline Unemployed & 556 & 37.0 & 193 & 24.1 & 363 & 51.8 \\
\hline Informally employed & 545 & 36.3 & 289 & 36.2 & 256 & 36.5 \\
\hline Employed in public or private sector & 395 & 26.3 & 317 & 39.6 & 78 & 11.1 \\
\hline Other & 5 & 0.4 & 1 & 0.1 & 4 & 0.6 \\
\hline \multicolumn{7}{|l|}{ Housing } \\
\hline Renting place & 733 & 48.8 & 393 & 49.1 & 340 & 48.5 \\
\hline Family home/own place & 434 & 28.9 & 171 & 21.4 & 171 & 37.5 \\
\hline Staying at someone else's place & 217 & 14.5 & 163 & 20.4 & 54 & 7.7 \\
\hline Other & 117 & 7.8 & 73 & 9.1 & 44 & 6.3 \\
\hline \multicolumn{7}{|l|}{ Living parents ${ }^{*}$} \\
\hline Both parents living & 1,015 & 67.6 & 565 & 70.6 & 450 & 64.2 \\
\hline One parent living & 391 & 26.1 & 186 & 23.3 & 205 & 29.2 \\
\hline No parents living & 93 & 6.2 & 48 & 6.0 & 45 & 6.2 \\
\hline \multicolumn{7}{|l|}{ Adult available to provide support ${ }^{\star}$} \\
\hline Both & 813 & 54.2 & 401 & 50.1 & 412 & 58.8 \\
\hline Emotionally & 317 & 21.1 & 137 & 17.1 & 180 & 25.7 \\
\hline Financially & 33 & 2.2 & 22 & 2.8 & 11 & 1.6 \\
\hline Neither & 336 & 22.4 & 239 & 29.9 & 97 & 13.8 \\
\hline \multicolumn{7}{|l|}{ Food insecurity ${ }^{\dagger}$} \\
\hline None & 1,160 & 77.3 & 634 & 79.3 & 526 & 75.0 \\
\hline Yes, rarely & 219 & 14.6 & 90 & 11.3 & 129 & 18.4 \\
\hline Yes, sometimes or often & 121 & 8.1 & 75 & 9.4 & 46 & 6.6 \\
\hline
\end{tabular}

\section{Personal and sexual history}

A total of 64 percent of AGYW enrolled reporting ever having sex (i.e., were sexually active) and the mean age of sexual debut was 16.8 years ( $s d \pm 2.5$ ). Almost two-thirds of AGYW overall reported having a current or past sexual partner that was five years older. Sixteen percent of AGYW reported being married or living together as if married. The mean age at marriage was 19.0 years ( $s d \pm 3.6$ ) and 17.3 years ( $s d \pm 2.4$ ) for AGYW enrolled from Addis Ababa and Gambella, respectively. For AYGW reporting being married or cohabitating as if married, 89 percent of AGYW from Addis Ababa reported they were exclusive while 58 percent of AGYW from Gambella reported exclusivity. Consistent condom use for vaginal sexual acts in the prior 12 months was low at 17 percent. Overall in the sample, 12 percent of AGYW reported engagement in transactional sex (exchanging sexual services for goods, services, or money), which was higher among AGYW aged 20-24 years (131/809, 16\%) than 15-19 years (44/690,6\%). The personal and sexual history characteristics of AGYW overall and by city are reported in Table 3. 
Table 3 Personal and sexual history of AGYW

\begin{tabular}{|c|c|c|c|c|c|c|}
\hline & \multirow{2}{*}{\multicolumn{2}{|c|}{$\begin{array}{c}\text { Total } \\
(n=1,501) \\
\text { Mean (SD) }\end{array}$}} & \multirow{2}{*}{\multicolumn{2}{|c|}{$\begin{array}{l}\text { Addis Ababa } \\
\qquad(n=800) \\
\text { Mean (SD) }\end{array}$}} & \multirow{2}{*}{\multicolumn{2}{|c|}{$\begin{array}{c}\text { Gambella } \\
(n=701) \\
\text { Mean (SD) }\end{array}$}} \\
\hline & & & & & & \\
\hline Age at marriage & \multicolumn{2}{|c|}{$17.9( \pm 3.0)$} & \multicolumn{2}{|c|}{$19.0( \pm 3.6)$} & \multicolumn{2}{|c|}{$17.3( \pm 2.4)$} \\
\hline Age at first sex & \multicolumn{2}{|c|}{$16.8( \pm 2.5)$} & \multicolumn{2}{|c|}{$17.0( \pm 2.9)$} & \multicolumn{2}{|c|}{$16.6( \pm 2.0)$} \\
\hline Average age difference with male partner & \multicolumn{2}{|c|}{$8.0( \pm 7.8)$} & \multicolumn{2}{|c|}{$8.5( \pm 8.4)$} & \multicolumn{2}{|c|}{$7.5( \pm 7.1)$} \\
\hline Age at first transactional sex & \multicolumn{2}{|c|}{$17.6( \pm 3.8)$} & \multicolumn{2}{|c|}{$18.2( \pm 2.7)$} & \multicolumn{2}{|c|}{$16.8( \pm 4.8)$} \\
\hline No. days per month engaging in transactional sex & \multicolumn{2}{|c|}{$16.1( \pm 9.2)$} & \multicolumn{2}{|c|}{$20.4( \pm 7.7)$} & \multicolumn{2}{|c|}{$10.4( \pm 7.9)$} \\
\hline \multirow[t]{2}{*}{ Average number of clients in 24-hr period } & \multicolumn{2}{|c|}{$2.5( \pm 2.5)$} & \multicolumn{2}{|c|}{$3.5( \pm 2.8)$} & \multicolumn{2}{|c|}{$1.2( \pm 0.7)$} \\
\hline & $\mathrm{n}$ & $\%$ & n & $\%$ & $\mathrm{n}$ & $\%$ \\
\hline Married or living together as if married & 245 & 16.3 & 87 & 10.9 & 158 & 22.5 \\
\hline AGYW or partner exclusive & 168 & 68.6 & 77 & 88.5 & 91 & 57.6 \\
\hline \multicolumn{7}{|l|}{ Sexual history ${ }^{\star}$} \\
\hline Never had sex & 538 & 35.8 & 297 & 37.1 & 241 & 34.4 \\
\hline Vaginal & 944 & 62.9 & 491 & 61.4 & 453 & 64.6 \\
\hline Anal & 1 & 0.1 & - & - & 1 & 0.1 \\
\hline Both & 17 & 1.1 & 11 & 1.4 & 6 & 0.9 \\
\hline \multicolumn{7}{|l|}{ Age disparate partner (male partner $5+$ years older) } \\
\hline$<5$ years & 338 & 35.1 & 172 & 34.3 & 166 & 36.1 \\
\hline$\geq 5$ years & 624 & 64.9 & 330 & 65.7 & 294 & 63.9 \\
\hline Vaginal sex in the last 12 months & 784 & 81.5 & 390 & 77.7 & 394 & 85.6 \\
\hline \multicolumn{7}{|l|}{ Condom use (vaginal sex) } \\
\hline Never & 388 & 49.6 & 194 & 49.7 & 194 & 49.4 \\
\hline Inconsistent & 264 & 33.7 & 120 & 30.8 & 144 & 36.6 \\
\hline Always & 131 & 16.7 & 76 & 19.5 & 55 & 14.0 \\
\hline Anal sex in the last 12 months & 16 & 1.7 & 11 & 2.2 & 5 & 1.1 \\
\hline Transactional sex & 175 & 11.7 & 101 & 12.6 & 74 & 10.6 \\
\hline
\end{tabular}

*missing $n=1$

\section{Reproductive health}

A total of 24 percent of AGYW enrolled reported a history of pregnancy, and 17 percent were mothers. Among those who reported ever having been pregnant, the mean age at first pregnancy was 18.4 years ( $s d \pm 2.5$ ), which was similar across cities, and 34 percent reported ever terminating a pregnancy. Overall, 67 percent of sexually active AGYW reported using any modern method of contraception, and 52 percent of sexually active AGYW were currently using a hormonal method and/or long-acting method of contraception (oral contraceptive pills, injectables, intrauterine device, or implant). Table 4 presents the reproductive health characteristics of AGYW overall and by city. 


\begin{tabular}{|c|c|c|c|c|c|c|}
\hline & \multicolumn{2}{|c|}{$\begin{array}{c}\text { Total } \\
(n=1,501)\end{array}$} & \multicolumn{2}{|c|}{$\begin{array}{l}\text { Addis Ababa } \\
\qquad(n=800)\end{array}$} & \multicolumn{2}{|c|}{$\begin{array}{c}\text { Gambella } \\
(n=701)\end{array}$} \\
\hline & $n$ & $\%$ & $n$ & $\%$ & $\mathrm{n}$ & $\%$ \\
\hline Ever pregnant & 353 & 23.5 & 164 & 20.5 & 189 & 27.0 \\
\hline \multicolumn{7}{|l|}{ No. of live births } \\
\hline 0 & 1248 & 83.1 & 700 & 87.5 & 548 & 78.2 \\
\hline 1 & 215 & 14.3 & 88 & 11.0 & 127 & 18.1 \\
\hline$\geq 2$ & 38 & 2.5 & 12 & 1.5 & 26 & 3.7 \\
\hline \multicolumn{7}{|l|}{ No. of children living } \\
\hline 0 & 3 & 1.2 & 2 & 2.1 & 1 & 0.7 \\
\hline 1 & 209 & 85.0 & 85 & 87.6 & 124 & 83.2 \\
\hline$\geq 2$ & 34 & 13.8 & 10 & 10.3 & 24 & 16.1 \\
\hline \multicolumn{7}{|l|}{ No. of children currently living with AGYW } \\
\hline 0 & 37 & 15.6 & 17 & 18.7 & 20 & 13.6 \\
\hline 1 & 184 & 77.3 & 69 & 75.8 & 115 & 78.2 \\
\hline$\geq 2$ & 17 & 7.1 & 5 & 5.5 & 12 & 8.2 \\
\hline Antenatal care during last pregnancy & 268 & 75.9 & 108 & 65.9 & 160 & 84.7 \\
\hline \multicolumn{7}{|l|}{ No. of terminations } \\
\hline 0 & 232 & 65.9 & 83 & 50.9 & 149 & 78.8 \\
\hline 1 & 111 & 31.5 & 73 & 44.8 & 38 & 20.1 \\
\hline$\geq 2$ & 9 & 2.6 & 7 & 4.3 & 2 & 1.1 \\
\hline \multicolumn{7}{|l|}{ Location of termination (>1 response possible) } \\
\hline At home or home of friend/family/traditional healer & 27 & 22.3 & 16 & 19.8 & 11 & 27.5 \\
\hline At a government clinic/hospital & 35 & 28.9 & 18 & 22.2 & 17 & 42.5 \\
\hline At a private clinic/hospital & 38 & 31.4 & 27 & 33.3 & 11 & 27.5 \\
\hline NGO clinic & 28 & 23.1 & 27 & 33.3 & 1 & 2.5 \\
\hline Serious health complication related to termination & 38 & 31.4 & 27 & 33.3 & 11 & 27.5 \\
\hline Currently pregnant & 27 & 1.8 & 14 & 1.8 & 13 & 1.9 \\
\hline Currently trying to become pregnant & 65 & 4.4 & 37 & 4.7 & 28 & 4.1 \\
\hline \multicolumn{7}{|l|}{ Importance of avoiding pregnancy } \\
\hline Not important & 269 & 19.1 & 202 & 27.0 & 67 & 10.2 \\
\hline Important & 1,097 & 77.9 & 545 & 72.9 & 552 & 83.6 \\
\hline Refusal & 1 & 0.1 & 1 & 0.1 & - & - \\
\hline Don’t know & 41 & 2.9 & - & - & 41 & 6.2 \\
\hline \multicolumn{7}{|l|}{ Current contraception method ( $>1$ response possible) } \\
\hline Birth control pill & 118 & 8.4 & 54 & 7.2 & 64 & 9.7 \\
\hline Intrauterine contraception device & 14 & 1.0 & 7 & 0.9 & 7 & 1.1 \\
\hline Injectable birth control & 363 & 25.8 & 143 & 19.1 & 220 & 33.4 \\
\hline Implant & 117 & 8.3 & 90 & 12.0 & 27 & 4.1 \\
\hline Male condom & 295 & 21.0 & 167 & 22.3 & 128 & 19.4 \\
\hline Diaphragm or cervical cap & 3 & 0.2 & 2 & 0.3 & 1 & 0.2 \\
\hline Post pill/emergency contraceptive & 117 & 8.3 & 87 & 11.7 & 30 & 4.6 \\
\hline Rhythm method & 27 & 1.9 & 19 & 2.5 & 8 & 1.2 \\
\hline Withdrawal & 5 & 0.4 & 5 & 0.7 & - & - \\
\hline Other $^{\dagger}$ & 15 & 1.1 & 11 & 1.5 & 4 & 0.6 \\
\hline
\end{tabular}

${ }^{*}$ Missing for $n=5$; ${ }^{\dagger}$ Other was composed of women reporting either abstinence or lactational amenorrhea 


\section{Health seeking behaviors}

Enrolled AGYW on average engaged in healthcare services $2.4( \pm 2.5)$ times in the 12 months prior to data collection. The majority of participants received healthcare services from governmental facilities. HIV testing was commonly reported, with 68 percent reporting receiving an HIV test in the prior year. Overall, 19 AGYW (2\%) self-reported a prior HIV diagnosis. For AGYW previously testing HIV positive, 90 percent (17/19) reported currently being on antiretroviral therapy. Testing for sexually transmitted infections in the prior year was 9 percent and selfreported symptoms of sexually transmitted infections was 6 percent among all AGYW enrolled.

\section{Table 5 Health seeking behaviors of AGYW}

\begin{tabular}{|c|c|c|c|c|c|c|}
\hline & \multicolumn{2}{|c|}{$\begin{array}{c}\text { Total } \\
(n=1,501) \\
\text { Mean (SD) }\end{array}$} & \multicolumn{2}{|c|}{$\begin{array}{l}\text { Addis Ababa } \\
\qquad(n=\mathbf{8 0 0}) \\
\text { Mean (SD) }\end{array}$} & \multicolumn{2}{|c|}{$\begin{array}{l}\text { Gambella } \\
(n=701) \\
\text { Mean (SD) }\end{array}$} \\
\hline \multirow{2}{*}{$\begin{array}{l}\text { No. of times received healthcare services in prior } 12 \\
\text { months }\end{array}$} & \multicolumn{2}{|c|}{$2.4( \pm 2.5)$} & \multicolumn{2}{|c|}{$2.2( \pm 2.1)$} & \multicolumn{2}{|c|}{$2.7( \pm 2.9)$} \\
\hline & $n$ & $\%$ & $\mathbf{N}$ & $\%$ & $\mathrm{n}$ & $\%$ \\
\hline \multicolumn{7}{|l|}{ Location for health services* } \\
\hline Governmental hospital/clinic & 1,179 & 78.6 & 603 & 75.4 & 576 & 82.2 \\
\hline Private hospital/clinic & 283 & 18.9 & 167 & 20.9 & 116 & 16.6 \\
\hline Nongovernmental organization & 16 & 1.1 & 13 & 1.6 & 3 & 0.4 \\
\hline Traditional healer & 3 & 0.2 & 3 & 0.4 & - & - \\
\hline Other & 19 & 1.3 & 13 & 1.6 & 6 & 0.9 \\
\hline Ever tested for $\mathrm{HIV}^{\dagger}$ & 1,019 & 68.0 & 553 & 69.1 & 466 & 66.5 \\
\hline Tested for HIV in prior 12 months ${ }^{\dagger}$ & 688 & 45.9 & 377 & 47.1 & 311 & 44.5 \\
\hline Ever tested positive for $\mathrm{HIV}^{\dagger}$ & 19 & 1.3 & 12 & 2.2 & 7 & 1.5 \\
\hline Ever started on antiretroviral therapy (ART) & 17 & 89.5 & 11 & 91.7 & 6 & 85.7 \\
\hline Currently on ART & 14 & 82.4 & 9 & 81.8 & 5 & 83.3 \\
\hline \multicolumn{7}{|l|}{ No. of days missed taking ART for any reason ${ }^{\ddagger}$} \\
\hline$\geq 95 \%$ adherence in past 14 days & 9 & 64.3 & 4 & 44.5 & 5 & 100 \\
\hline$<95 \%$ adherence in past 14 days & 2 & 14.3 & 2 & 22.2 & - & - \\
\hline Don't know & 3 & 21.4 & 3 & 33.3 & - & - \\
\hline Ever tested for STI in prior 12 month $^{*}$ & 137 & 9.1 & 93 & 11.6 & 44 & 6.3 \\
\hline Ever told by doctor/healthcare provider of STI & 37 & 27.1 & 17 & 18.3 & 20 & 45.5 \\
\hline Ever had symptoms of STI in prior 12 months ${ }^{\dagger}$ & 95 & 6.3 & 62 & 7.8 & 33 & 4.7 \\
\hline STI infection treated by doctor/healthcare provider & 55 & 58.5 & 29 & 47.5 & 26 & 78.8 \\
\hline
\end{tabular}

${ }^{*}$ missing for $n=1 ;{ }^{\dagger}$ missing $n=2 ;{ }^{\ddagger}$ missing $n=3$

\section{Self-perceived risk}

AGYW were asked what they thought the chances were of getting HIV in the next six months on a scale of 0 to 100 (zero meaning no risk). The self-perceived HIV risk among AGYW enrolled was low. The mean self-perceived risks are presented in Table 6. 
Table 6 Self-perceived HIV risk among AGYW

\begin{tabular}{|lccc|}
\hline & $\begin{array}{c}\text { Total } \\
(n=1,501)\end{array}$ & $\begin{array}{c}\text { Addis Ababa } \\
(n=800)\end{array}$ & $\begin{array}{c}\text { Gambella } \\
(n=701)\end{array}$ \\
Self-perceived HIV risk in next 6 months $(1-100)$ & $16.6( \pm 20.1)$ & $13.5( \pm 22.4)$ & $20.5( \pm 27.5)$ \\
\hline
\end{tabular}

\section{Physical and sexual vulnerability}

About 26 percent of participants overall reported a history of physical violence, 30 percent of participants from Addis Ababa and 21 percent from Gambella. Physical violence was defined as being physically hurt (pushed, shoved, slapped, hit, kicked, choked, or otherwise physically hurt) by someone else. The main perpetrators of violence included husbands, boyfriends, or any current or past sexual partners, family members, and strangers. Table $\mathbf{7}$ presents the physical and sexual vulnerability of AGYW overall and by city.

\section{Table 7 Physical and sexual vulnerability of AGYW}

\begin{tabular}{|c|c|c|c|c|c|c|}
\hline & \multicolumn{2}{|c|}{$\begin{array}{c}\text { Total } \\
(n=1,501)\end{array}$} & \multicolumn{2}{|c|}{$\begin{array}{l}\text { Addis Ababa } \\
\qquad(n=800)\end{array}$} & \multicolumn{2}{|c|}{$\begin{array}{l}\text { Gambella } \\
(n=701)\end{array}$} \\
\hline & n & $\%$ & $n$ & $\%$ & n & $\%$ \\
\hline History of physical violence & 395 & 26.3 & 247 & 30.9 & 148 & 21.1 \\
\hline \multicolumn{7}{|l|}{ Frequency of physical violence in past 12 months } \\
\hline 0 times & 74 & 18.8 & 46 & 18.8 & 28 & 18.9 \\
\hline $1-5$ times & 299 & 76.1 & 183 & 74.7 & 116 & 78.4 \\
\hline$>5$ times & 20 & 5.1 & 16 & 6.5 & 4 & 2.7 \\
\hline \multicolumn{7}{|l|}{ Perpetrator of physical violence in past 12 months } \\
\hline $\begin{array}{l}\text { Husband, boyfriend or any current or past sexual } \\
\text { partner }\end{array}$ & 110 & 27.8 & 62 & 25.0 & 48 & 32.4 \\
\hline Teacher & 21 & 5.3 & 20 & 8.1 & 1 & 0.7 \\
\hline Classmate & 37 & 9.4 & 20 & 8.1 & 17 & 11.5 \\
\hline Friend & 18 & 4.6 & 16 & 6.5 & 2 & 1.4 \\
\hline Family member & 101 & 25.6 & 68 & 27.5 & 33 & 22.3 \\
\hline Community or religious leader & 8 & 2.0 & 7 & 2.8 & 1 & 0.7 \\
\hline Someone from your neighborhood & 63 & 15.9 & 37 & 14.9 & 26 & 17.6 \\
\hline Stranger & 92 & 23.2 & 64 & 25.8 & 28 & 18.9 \\
\hline Other & 23 & 5.8 & 20 & 8.1 & 3 & 2.0 \\
\hline History of sexual violence & 145 & 9.7 & 110 & 13.8 & 35 & 5.0 \\
\hline
\end{tabular}

\section{Alcohol consumption}

Overall, 36 percent of AGYW reported alcohol consumption in the prior 12 months. Of those who reported drinking in the prior year, 41 percent reported binge drinking at least once per week. Table 8 presents alcohol consumption among AGYW overall and by city. 


\begin{tabular}{|c|c|c|c|c|c|c|}
\hline & \multicolumn{2}{|c|}{$\begin{array}{c}\text { Total } \\
(n=1,501)\end{array}$} & \multicolumn{2}{|c|}{$\begin{array}{l}\text { Addis Ababa } \\
\qquad(n=800)\end{array}$} & \multicolumn{2}{|c|}{$\begin{array}{c}\text { Gambella } \\
(n=701)\end{array}$} \\
\hline & $\mathrm{n}$ & $\%$ & $n$ & $\%$ & $\mathrm{n}$ & $\%$ \\
\hline \multicolumn{7}{|c|}{ Alcohol consumption in preceding 12 months ${ }^{*}$} \\
\hline Never & 995 & 63.7 & 456 & 57.1 & 499 & 71.2 \\
\hline Once a week or less & 383 & 25.5 & 249 & 31.1 & 134 & 19.1 \\
\hline Two or more times a week & 162 & 10.8 & 94 & 11.8 & 68 & 9.7 \\
\hline \multicolumn{7}{|c|}{ No. of alcoholic drinks on typical drinking day } \\
\hline $1-2$ & 300 & 55.0 & 212 & 61.8 & 88 & 43.6 \\
\hline $3-6$ & 211 & 38.7 & 115 & 33.5 & 96 & 47.5 \\
\hline$>7$ & 33 & 6.1 & 15 & 4.4 & 18 & 8.9 \\
\hline Don't know & 1 & 0.2 & 1 & 0.3 & - & - \\
\hline \multicolumn{7}{|c|}{ Binge drinking ( 4 or more drinks at a given time) } \\
\hline Never & 143 & 26.2 & 113 & 32.9 & 30 & 14.9 \\
\hline Less than monthly & 59 & 10.8 & 43 & 12.5 & 16 & 7.9 \\
\hline Monthly & 122 & 22.4 & 79 & 23.0 & 43 & 21.3 \\
\hline Weekly & 125 & 22.9 & 55 & 16.0 & 70 & $34.7^{\wedge}$ \\
\hline Daily or almost daily & 96 & 17.6 & 53 & 15.5 & 43 & 21.3 \\
\hline
\end{tabular}

${ }^{*}$ Missing for $n=1$

\section{Social support and mental health}

The social support survey scale (MOS-SSS) assessed various dimensions of social support experienced by AGYW. ${ }^{3}$ Overall, social support was assessed using a social support scale ranging from one to 100, where 100 indicated complete social support. Among AGYW enrolled, selfreported social support was 60.1 (sd \pm 33.0 ) out of 100 (Table 9).

The Attitudes Toward Women Scale for Adolescents (AWSA), which is based on the Attitudes Toward Women Scale, assesses attitudes about the rights and roles of women in society and about gender (Zinta et al. 2011). AWSA scores range from more traditional views (lower scoresminimum score equals 1 ) to egalitarian views (high scores-maximum score equals 4) (Spence and Helmreich 1972).AGYW enrolled in the study were found to have scores suggestive of attitudes toward women which do not ascribe strongly to stereotypical gender roles, with a mean of $2.8( \pm 0.4)$.

Based on the PHQ-9 screening for mental health, one-quarter of AGYW reported minor or major symptoms of depression. Results were similar across age groups (not shown), though statistically differed between Addis Ababa and Gambella ( $X^{2} 23.46$, $p$-value <0.001).

${ }^{3}$ https://www.rand.org/health-care/surveys_tools/mos/social-support.html 
Table 9 Social support and mental health screening among AGYW

\begin{tabular}{|c|c|c|c|c|c|c|}
\hline & \multicolumn{2}{|c|}{$\begin{array}{c}\text { Total } \\
(n=1,501) \\
\text { Mean (SD) }\end{array}$} & \multicolumn{2}{|c|}{$\begin{array}{l}\text { Addis Ababa } \\
\quad(n=\mathbf{8 0 0}) \\
\text { Mean (SD) }\end{array}$} & \multicolumn{2}{|c|}{$\begin{array}{c}\text { Gambella } \\
(n=701) \\
\text { Mean (SD) }\end{array}$} \\
\hline Social support scale (0-100), mean (sd) & \multicolumn{2}{|c|}{$60.1( \pm 33.0)$} & \multicolumn{2}{|c|}{$58.6( \pm 34.3)$} & \multicolumn{2}{|c|}{$61.8( \pm 31.4)$} \\
\hline Attitudes Toward Women Scale for Adolescents & \multicolumn{2}{|c|}{$2.8( \pm 0.4)$} & \multicolumn{2}{|c|}{$2.9( \pm 0.4)$} & \multicolumn{2}{|c|}{$2.7( \pm 0.3)$} \\
\hline PHQ-9 Screen ${ }^{*}$ & n & $\%$ & $\mathrm{n}$ & $\%$ & n & $\%$ \\
\hline No symptoms & 780 & 52.0 & 370 & 46.2 & 410 & 58.5 \\
\hline Minimal symptoms & 340 & 22.7 & 199 & 24.9 & 141 & 20.1 \\
\hline Minor depression/major depression, mild & 241 & 16.1 & 143 & 17.9 & 98 & 14.0 \\
\hline Major depression, moderate & 114 & 7.6 & 71 & 8.9 & 43 & 6.1 \\
\hline Major depression, severe & 24 & 1.6 & 16 & 2.0 & 8 & 1.5 \\
\hline
\end{tabular}

*missing $n=2$

\section{Biological testing}

The HIV prevalence overall was 2.7 percent (95\% Cl 2.0-3.6) $(2.1 \%$ in Addis Ababa [95\% Cl 1.3-3.4] and 3.3\% in Gambella [95\% CI 2.2-4.9], respectively. Among all AGYW enrolled, the syphilis prevalence was 2.4 percent $(95 \% \mathrm{Cl} 1.7-3.3)$ and the chlamydia prevalence was 5.4 percent $(95 \% \mathrm{Cl}$ 4.3-6.7). The prevalence of any STI (HIV, syphilis, or chlamydia) among all study participants was 10 percent (95\% Cl 8.6-11.7\%). Table 10 presents the HIV, syphilis, and chlamydia prevalence among AGYW by city and sub-city in Addis Ababa. In terms of co-infections, 6/151 (4\%) AGYW with an STI were co-infected; all AGYWs with a co-infection were living with HIV, 4 with a syphilis co-infection and 2 with a chlamydia co-infection.

Table 10 Prevalence of HIV, syphilis, and chlamydia among AGYW

\begin{tabular}{|lccccc|}
\hline & $n$ & $\begin{array}{c}\text { HIV prevalence } \\
\%[95 \% \mathrm{Cl}]\end{array}$ & $\begin{array}{c}\text { Syphilis } \\
\text { prevalence } \\
\%[95 \% \mathrm{Cl}]\end{array}$ & $\begin{array}{c}\text { Chlamydia } \\
\text { prevalence } \\
\%[95 \% \mathrm{Cl}]\end{array}$ & $\begin{array}{c}\text { Prevalence of } \\
\text { any STI }^{*}\end{array}$ \\
\hline Addis Ababa & 800 & $2.1[1.3-3.4]$ & $2.0[1.2-3.2]$ & $5.8[4.4-6.6]$ & $10.1[8.6-11.7]$ \\
Addis Ketema & 338 & $2.7[1.4-5.1]$ & $3.3[1.8-5.8]$ & $11.6[8.6-15.5]$ & $17.2[13.5-21.6]$ \\
Akaki Kaliti & 282 & $2.5[1.2-5.2]$ & $1.4[0.5-3.7]$ & $0.7[0.2-2.8]$ & $4.3[2.4-7.4]$ \\
Kolfe Keranio & 184 & $0.5[0.1-3.8]$ & $0.6[0.1-3.9]$ & $3.3[1.4-7.2]]$ & $4.3[2.1-8.5]$ \\
Gambella & 701 & $3.3[2.2-4.9]$ & $2.9[1.8-4.4]$ & $4.9[3.5-6.7]$ & $10.4[8.4-12.9]$ \\
\hline
\end{tabular}

${ }^{*}$ HIV, syphilis, or chlamydia

There was a marked difference in HIV prevalence between age groups. Among girls aged 15-19 years, HIV prevalence overall was 0.6 percent [95\% $\mathrm{Cl}$ : 3.2-6.1]; it was 4.5 percent [95\% Cl: $3.2-$ 6.1] among young women aged 20-24 years. Trends were similar in Addis Ababa and Gambella, where HIV prevalence among 15- to 19-year-olds was 0.3 percent [95\% $\mathrm{Cl}: 0.0-2.1$ ] and 0.8 percent [95\% Cl: 0.3-2.6], respectively, and HIV prevalence among 20- to 24-year-olds was 3.4 percent [95\% Cl: 2.1-5.5] and 5.8 percent [95\% $\mathrm{Cl}: 3.9-8.9$ ], respectively. Among AGYW engaged in transactional sex, overall HIV prevalence was 12.1 percent [95\% 8.0-17.8\%]. Finally, among out-of-school AGYW, HIV prevalence overall was 3.4 percent [95\% $\mathrm{Cl}: 2.4-4.7$ ]. HIV prevalence was similar among 15- to 19-year-olds when comparing in and out-of-school girls, however among 
20- to 24-year-old young women, HIV prevalence was 2.6 percent [95\% Cl: $1.2-5.7$ ] among young women in school, doubling to 5.2 percent [95\% Cl: 3.7-7.3\%] among those out-of-school.

The HIV heatmap and HIV prevalence by venue are depicted in Figure $\mathbf{7}$ and Figure $\mathbf{8}$ for the three sub-cities in Addis Ababa. The heat maps for Addis Ababa illustrate the woredas or districts of HIV concentration. Additionally, HIV prevalence maps illustrate the venues with the highest HIV prevalence. Addis Ketema had the largest number of venues with an elevated HIV prevalence. Understanding the distribution of HIV and STI prevalence across geographic areas can aid in targeted programming, intervention development, and resource allocation.

Figure 7 Heat map of HIV prevalence in Addis Ababa^

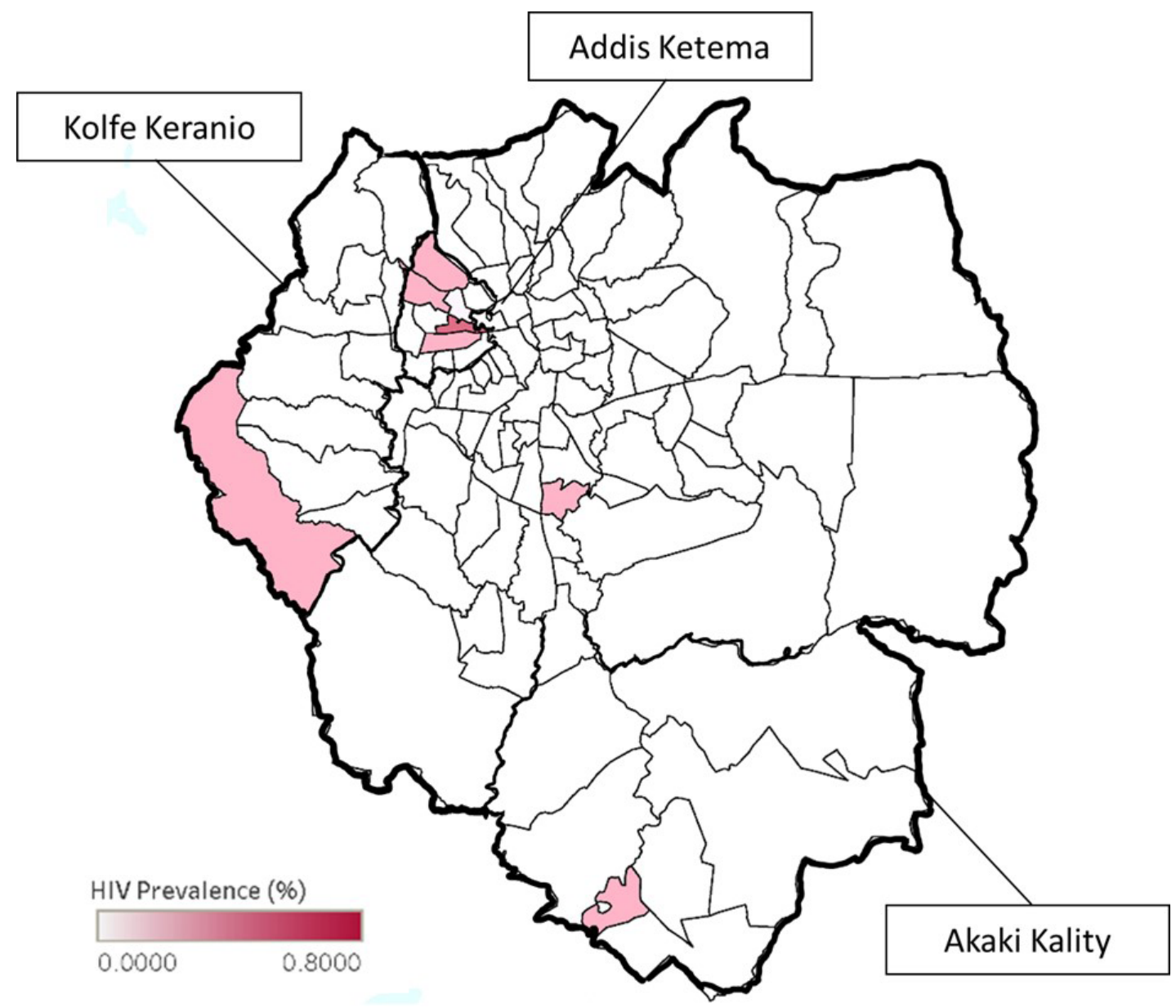

^The map presents data collected exclusively in Kolfe Keranio, Addis Ketema, and Akaki Kality. 
Figure 8 HIV prevalence by venue in Addis Ababa^

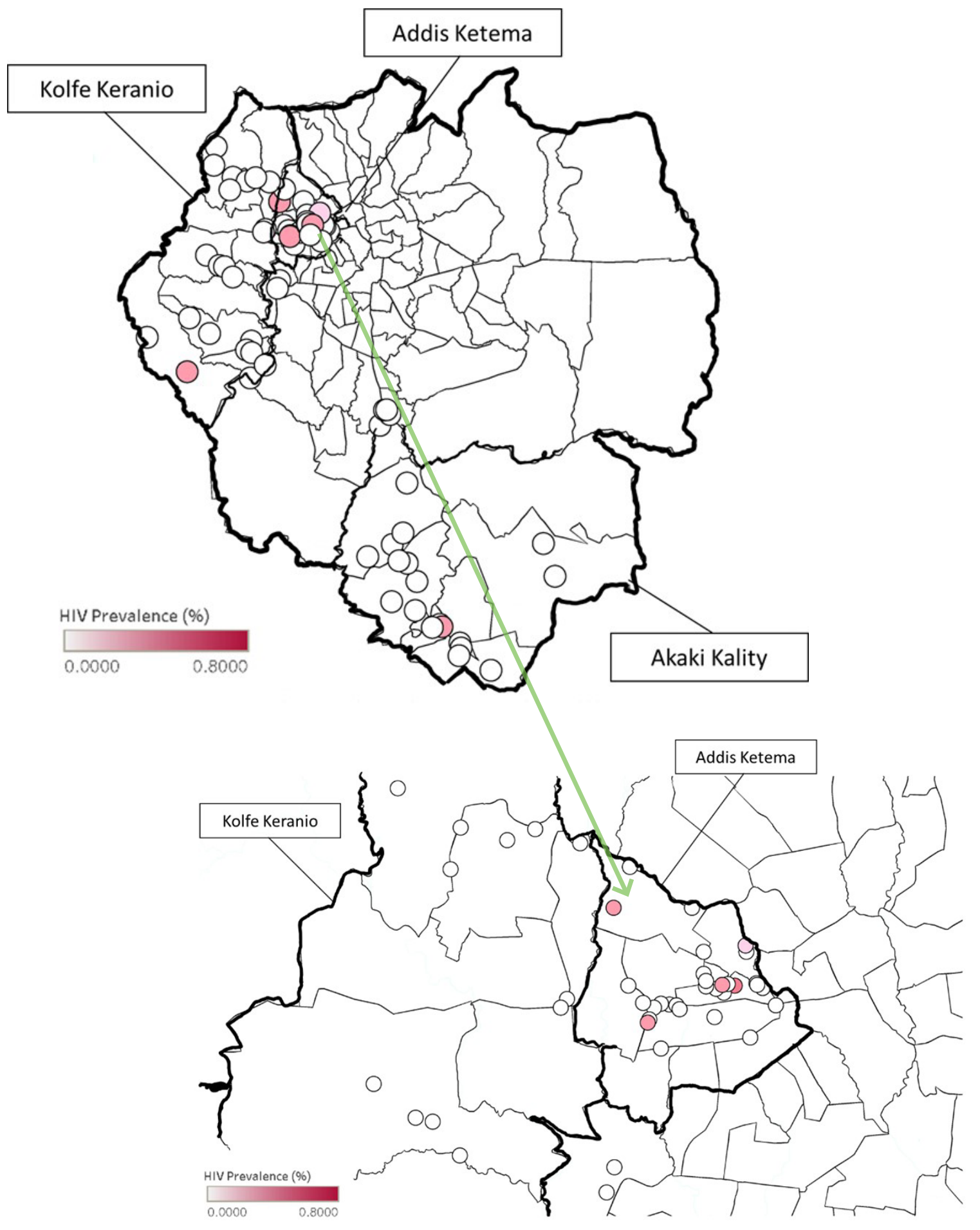

${ }^{\wedge}$ The map presents data collected exclusively in Kolfe Keranio, Addis Ketema, and Akaki Kality.

The syphilis heatmap for Addis Ababa is illustrated in Figure 9 and prevalence by venue in Figure 10. Despite limited co-infection rates, there is notable overlap between the hotspots on the maps for both HIV and syphilis. 
Figure 9 Heat map of syphilis prevalence in Addis Ababa^

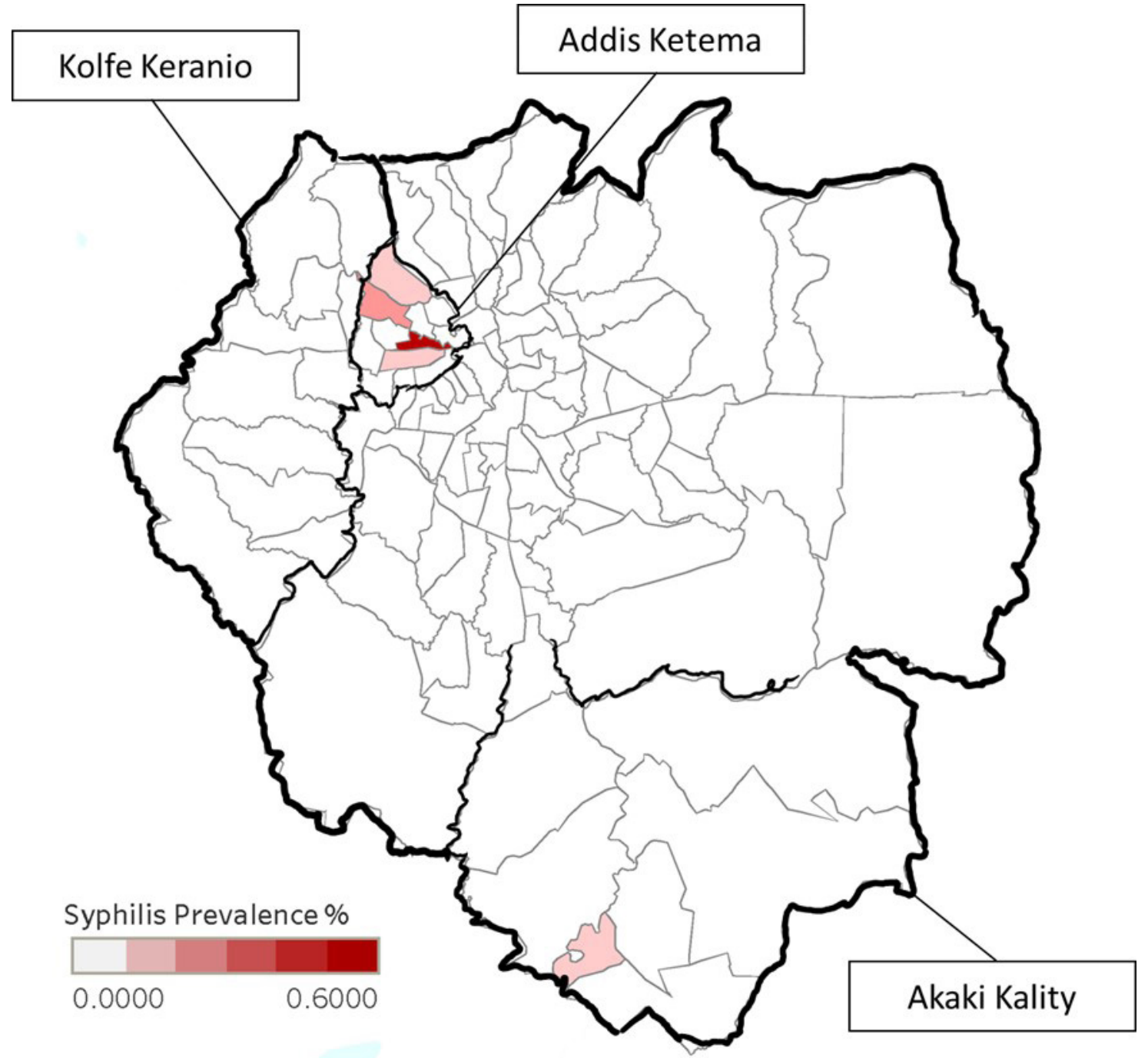

$\wedge^{\wedge}$ The map presents data collected exclusively in Kolfe Keranio, Addis Ketema, and Akaki Kality. 
Figure 10 Prevalence of syphilis in Addis Ababa by venue ${ }^{\wedge}$

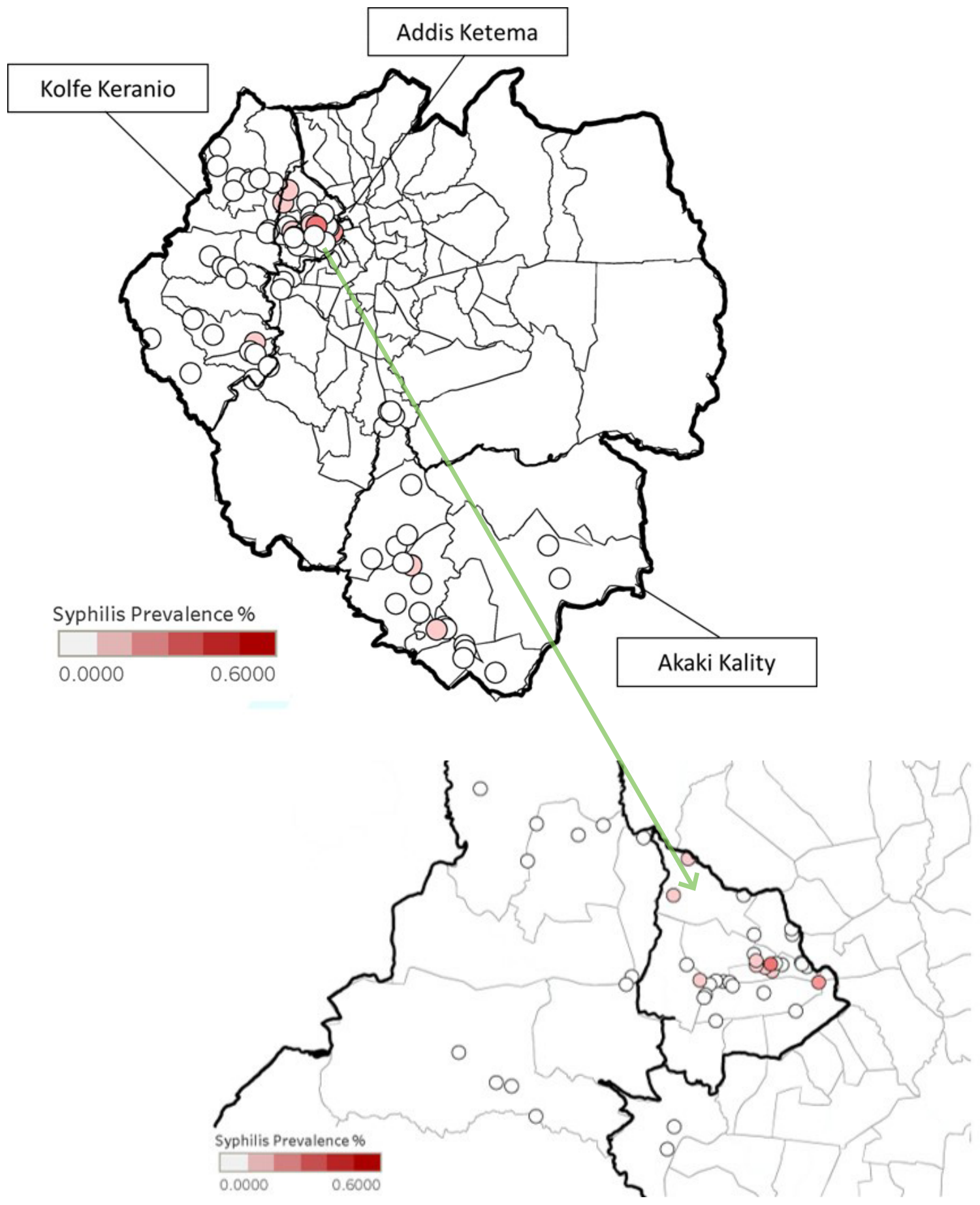

^The map presents data collected exclusively in Kolfe Keranio, Addis Ketema, and Akaki Kality.

Chlamydia results are mapped by woreda for Addis Ababa in Figure $\mathbf{1 1}$ and according to prevalence by venue in Figure 12. 
Figure 11 Heat map of chlamydia prevalence in Addis Ababa^

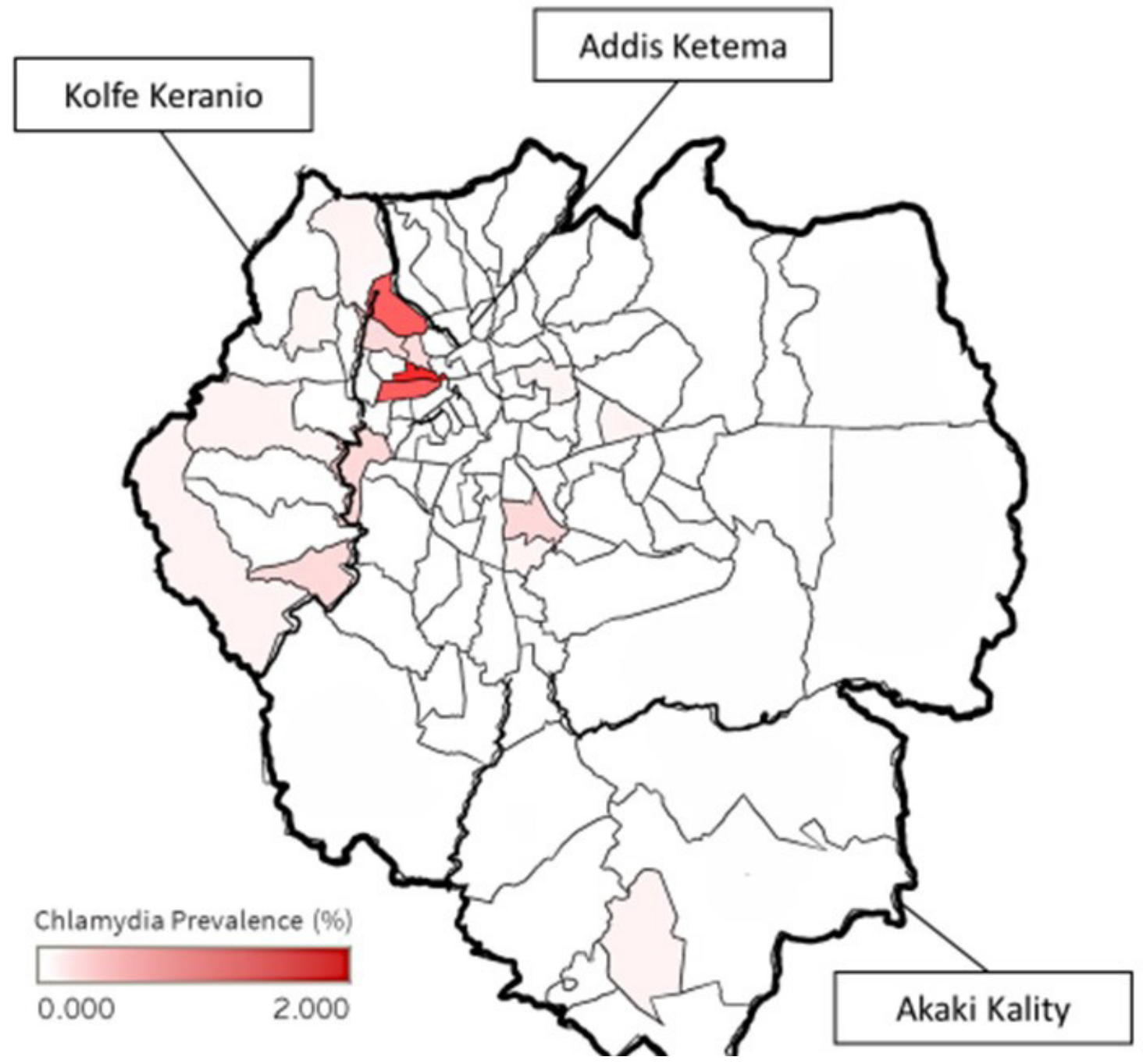

^The map presents data collected exclusively in Kolfe Keranio, Addis Ketema, and Akaki Kality. 


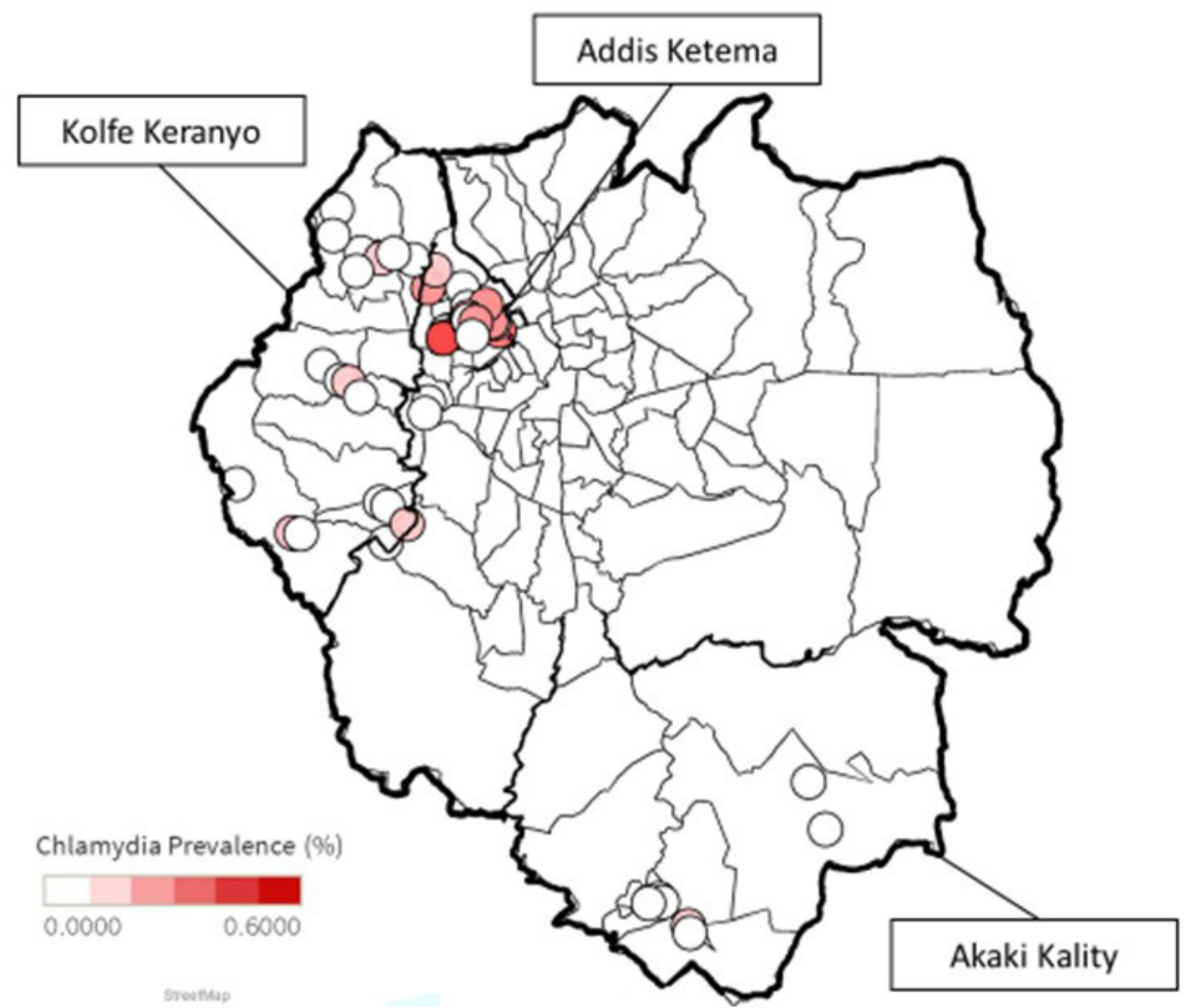

^The map presents data collected exclusively in Kolfe Keranio, Addis Ketema, and Akaki Kality.

In Gambella, all prevalence maps are presented by venue. Woreda or other sub-unit administrative boundaries for Gambella were not publicly available online for utilization during the mapping process. Thus, all prevalence mapping for Gambella is done by venue. Figure 13 illustrates HIV, syphilis, and chlamydia prevalence side-by-side. The maps show that while there are particular hotspots within Gambella, there is heterogeneity in terms of where different infections are most prevalent. 
Figure 13 Prevalence of sexually transmitted infections by venue in Gambella for

(a) HIV prevalence; (b) syphilis prevalence; and (c) chlamydia prevalence
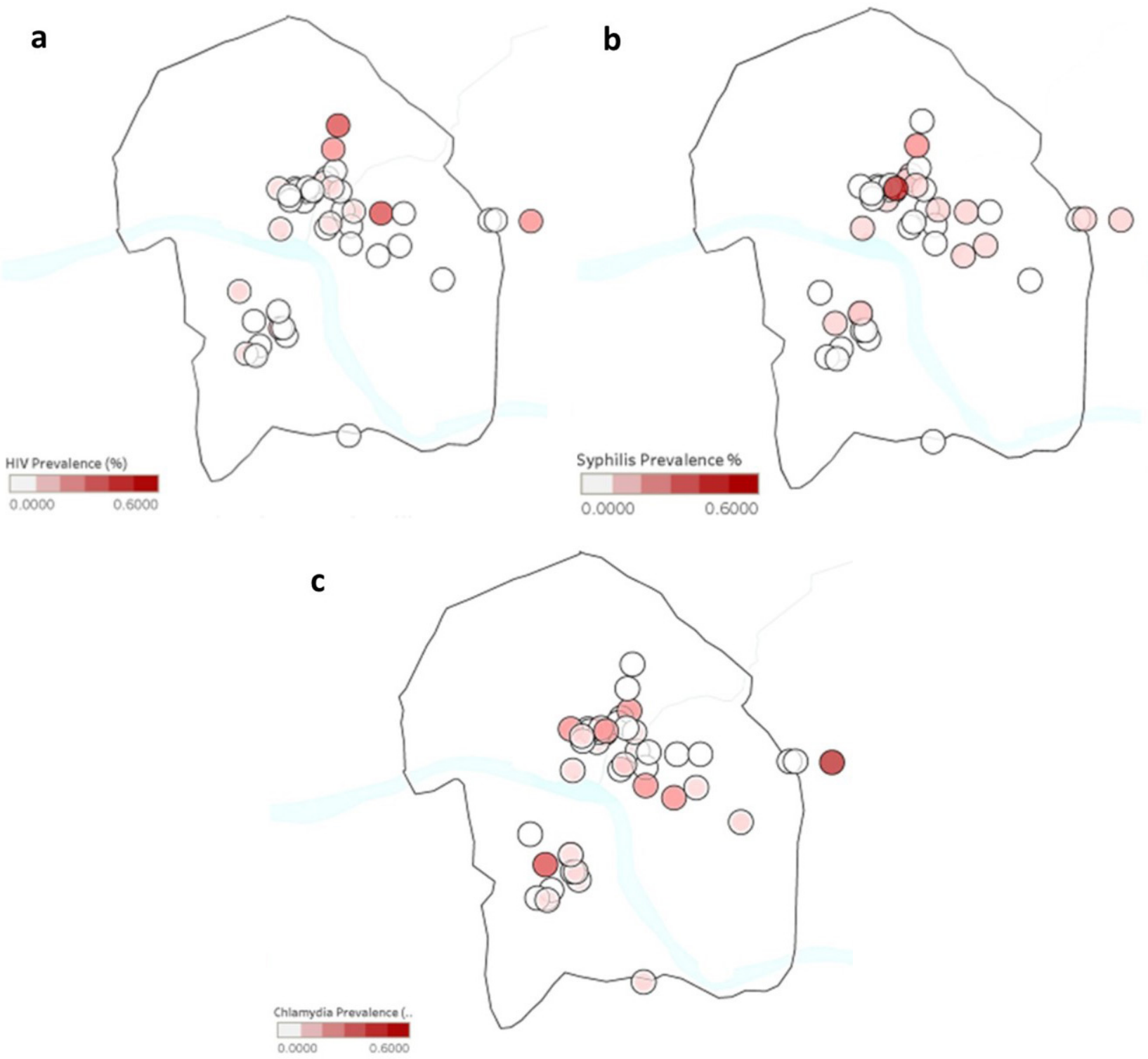


\section{CONCLUSION}

There is a need to better understand HIV and STI-related vulnerabilities among AGYW in Ethiopia, and data reported here provide critical inputs to expand our understanding about the epidemic and risk among young women in Addis Ababa and Gambella. Overall, 2.7 percent of AGYW we interviewed were living with HIV, which was higher among 20- to 24-year-old young women (16\%) than 15- to 19-year-old girls (6\%). Although co-infection was uncommon, 10 percent of all AGYW had evidence of any STI, again demonstrating the level of sexual risk young women are experiencing. Despite the risks observed, risk perception was low among AGYW, and 84 percent of sexually active AGYW reported never using or inconsistent condom use in the prior 12 months.

AGYW are a priority population that experience a disproportionate level of new HIV infections compared to same-aged males and the overall adult population. Addressing the unmet prevention needs of AGYW within Ethiopia, as well as addressing the heterogeneity in overall STI risk and vulnerability, will be necessary to combat the epidemic by averting new incident infections and reducing the risk of onward transmission through treatment. Efforts to identify and reach vulnerable AGYW-particularly those aged 15-24 years, out of school, and engaged in transactional sex-are warranted based on these data. Contraception coverage, including coverage of hormonal and/or long-acting methods, was moderately high among AGYW, indicating a potential opportunity for integration of further HIV prevention methods, including pre-exposure prophylaxis, into these services.

Various sources of vulnerability were identified among the sample, including being out-ofschool, engagement in transactional sex, migration, substantial reporting of experiences with physical or sexual violence, and a moderate amount of food insecurity during the prior month. AGYW did commonly receive emotional or financial support from adults, however, and many AGYW expressed empowered attitudes related to the role of women in society. Young women were commonly engaged in HIV testing, suggesting successful penetration of HIV testing within this population. Seventeen percent of AGYW in this study were mothers, an elevated proportion compared to national population-based data in which 10 percent of AYGW are mothers (CSA and ICF 2016).

Venue-based TLS was an effective method to systematically identify and recruit predominantly out-of-school AGYW and could be used programmatically as a method to reach AGYW with prevention and treatment services. TLS was more effective at reaching out-of-school AGYW in Addis Ababa, however, than in Gambella where just over half of the population enrolled was out-of-school. It is unclear why fewer AGYW were out of school in Gambella, but this may have been related to different dynamics across cities (Gambella being a less urban environment), the timing of the survey (when school was not in session), and/or safety limitations preventing data collection at late evening hours, when potentially more AGYW not in school might be visiting venues. Nevertheless, TLS led to the identification of a substantial number of venues, a diverse sample of geographic locations, various venue types, and numerous AGYW at high risk for HIV infection in both Addis Ababa and Gambella. The method also allowed for geo-mapping across 
the cities. Hotspots for HIV and STI infections were observed, with substantial overlap between HIV and other STI hotspots in Addis Ababa and slightly more varied patterns of HIV, syphilis, and chlamydia clustering in Gambella. Taken together with results of the health facility mapping, geographic areas of vulnerability and gaps in existing service delivery can be identified.

The importance of substantial community engagement is critical to ensuring safety while implementing a venue-based approach. In addition to community engagement activities, the presence of AGYW CAB members within the community, and dissemination of letters to police and key stakeholders, ensuring messages are communicated across and within stakeholder groups is paramount. Moreover, engagement of youth activities and men were found to be important and relevant for conducting research among AYGW in Ethiopia.

In closing, these data suggest that this sample of predominantly out-of-school AGYW were at increased risk and vulnerability for HIV and STI in Addis Ababa and Gambella, highlighting the need for intervention. Moreover, geographic differences in vulnerabilities and HIV, syphilis, and chlamydia infections were identified. A refined understanding of the heterogeneity of HIV risk and vulnerability among AGYW can be leveraged for HIV programming nationally. Moreover, geospatial mapping of HIV, syphilis, and chlamydia among AGYW in Addis Ababa and Gambella can be used to refine and prioritize areas for future HIV prevention programming in order to optimize resource allocation. 


\section{REFERENCES}

Byrne, Zinta S., et al. 2011. "A comparison of responses on the Attitudes Toward Women Scale and Attitudes Toward Feminism Scale," Measurement and Evaluation in Counseling and Development 44(4): 248-264. doi: 10.1177/0748175611418982

Central Statistical Agency (CSA) [Ethiopia] and ICF. 2016. Ethiopia Demographic and Health Survey 2016. Addis Ababa, Ethiopia, and Rockville, Maryland, USA: CSA and ICF. Available at: https://dhsprogram.com/pubs/pdf/ FR328/FR328.pdf

Chimbindi, N. et al. 2018. "Persistently high incidence of HIV and poor service uptake in adolescent girls and young women in rural KwaZulu-Natal, South Africa prior to DREAMS," PLoS One 13(10): e0203193. doi: 10.1371/ journal.pone.0203193

De Regt, M. 2016. “Time to look at girls: Adolescent girls' migration in Ethiopia.” Unpublished report.

Deribew, Amare. 2009. "Distribution of most-at-risk population groups and their perceptions towards HIV/AIDS: A baseline survey in Amhara Region for the implementation of mobile HIV counseling and testing." Bethesda, MD: Private Sector Program-Ethiopia, Abt Associates Inc.

Erulkar, A. et al. 2006. "Migration and vulnerability among adolescents in slum areas of Addis Ababa, Ethiopia," Journal of Youth Studies 9(3): 361-374. doi: 10.1080/13676260600805697

Erulkar A. 2017. "Girmay medhin, and lemi negeri, the journey of out-of-school girls in Ethiopia: examining migration, livelihoods, and HIV." Addis Ababa: Population Council.

Ethiopia HIV/AIDS Prevention \& Control Office (FHAPCO)and Global AIDS Monitoring \& Evaluation Team (GAMET). 2008. "HIV / AIDS in Ethiopia-an epidemiological synthesis," World Bank Global HIV/AIDS Program. Washington, DC: World Bank.

Ezra, M. 2001. “Ecological degradation, rural poverty, and migration in Ethiopia: A contextual analysis," Policy Research Division Working Paper. New York: Population Council.

Ferede, A. and A. Erulkar. 2009. "Adolescent girls in urban Ethiopia: Vulnerability \& opportunity." Addis Ababa, Ethiopia: Population Council.

Fleischman, J. and Peck, K. 2015. "Addressing HIV risk in adolescent girls and young women." Washington, DC: Center for Strategic \& International Studies.

Kuringe, E. et al. 2019. "Prevalence and correlates of depression and anxiety symptoms among out-of-school adolescent girls and young women in Tanzania: A cross-sectional study," PLoS One 14(8): e0221053. doi: 10.1371/journal.pone.0221053

Measure Evaluation Project. 2005. “PLACE: Priorities for Local AIDS Control Efforts.”

PHIA Project. 2018. “Ethiopia population-based HIV impact assessment EPHIA 2017-2018," Summary Sheet: Preliminary Findings. New York: ICAP, Columbia University. Available at: https://phia.icap.columbia.edu/wpcontent/uploads/2018/12/3511\%E2\%80\%A2EPHIA-Summary-Sheet_v30.pdf

Spence, JT and RL Helmreich. 1972. "The attitudes toward women scale: an objective instrument to measure attitudes toward the rights and roles of women in contemporary society," JSAS: Catalog of Selected Documents in Psychology 2: 667-68.

UNAIDS. 2016. “Key Population Atlas,” in Data Sources. Geneva: UNAIDS.

van Blerk, L. 2008. “Poverty, migration and sex work: Youth transitions in Ethiopia," Area 40(2): 245-253. doi: 10.1111/j.1475-4762.2008.00799.x

Zuma, T. et al. Date unknown. "Exploring perceptions and experiences of adolescent girls and young women participating in DREAMS in rural northern KwaZulu-Natal, South Africa," poster. Available at: https://www.Ishtm. ac.uk/files/exploring-perceptions-and-experiences.pdf 
APPENDIX 1

HEALTH FACILITIES MAPPED IN

ADDIS ABABA, BAHIR DAR, AND

GAMBELLA 


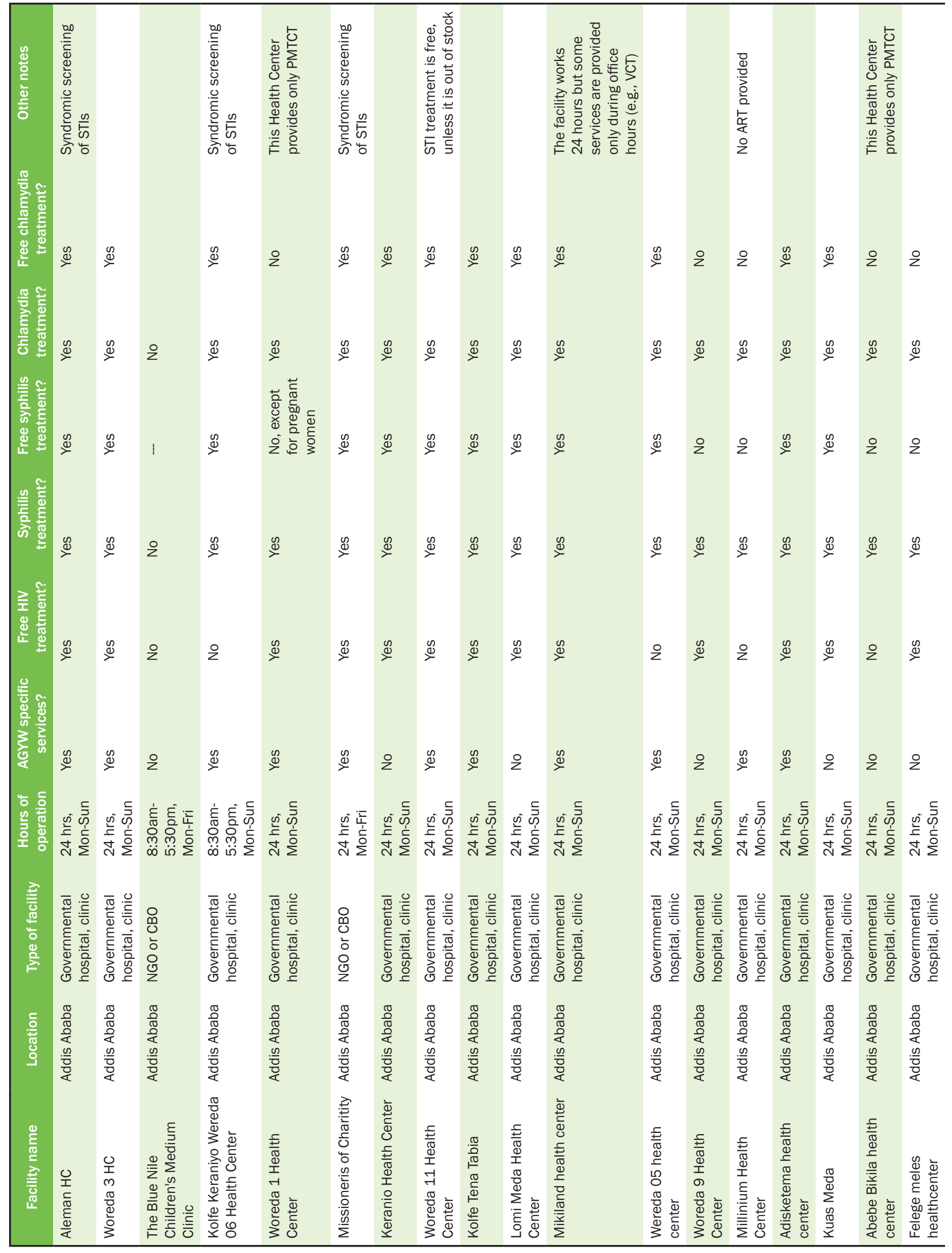




\begin{tabular}{|c|c|c|c|c|c|c|c|c|c|c|c|c|c|}
\hline 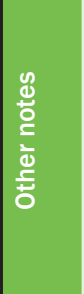 & 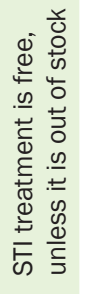 & & 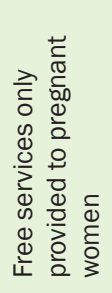 & 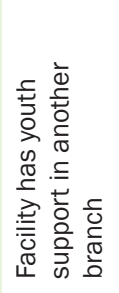 & & & 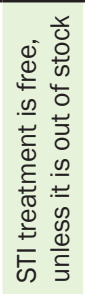 & & & & 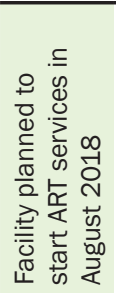 & & 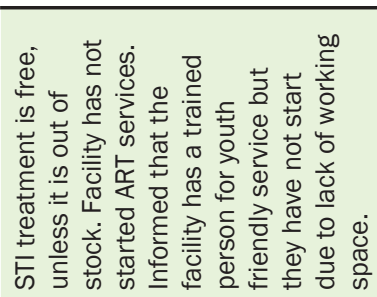 \\
\hline 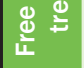 & $\stackrel{\mathscr{D}}{\nu}$ & $\stackrel{\mathscr{D}}{\nu}$ & z & $\stackrel{\infty}{\nu}$ & $\stackrel{\mathscr{N}}{\nu}$ & $\stackrel{\infty}{\nu}$ & $\stackrel{\infty}{\nu}$ & $\stackrel{\mathscr{J}}{x}$ & $\stackrel{0}{\nu}$ & z & $\stackrel{\circ}{z}$ & $\stackrel{0}{z}$ & 운 \\
\hline 등 & $\stackrel{\mathscr{U}}{\nu}$ & $\stackrel{\mathscr{0}}{\rightleftharpoons}$ & $\stackrel{\mathscr{J}}{\nu}$ & $\stackrel{\infty}{\nu}$ & $\stackrel{\infty}{\nu}$ & $\stackrel{\infty}{\nu}$ & $\stackrel{\infty}{\nu}$ & $\stackrel{\infty}{\nu}$ & $\stackrel{0}{\nu}$ & $\stackrel{\infty}{\nu}$ & $\stackrel{\infty}{\nu}$ & $\stackrel{\infty}{\nu}$ & $\stackrel{\infty}{\varnothing}$ \\
\hline 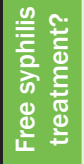 & $\stackrel{\mathscr{0}}{\varnothing}$ & 1 & z & $\stackrel{\mathscr{0}}{\nu}$ & $\stackrel{\infty}{\nu}$ & $\stackrel{\mathscr{0}}{\nu}$ & $\stackrel{\mathscr{D}}{\nu}$ & $\stackrel{\mathscr{D}}{\nu}$ & $\stackrel{\infty}{\nu}$ & 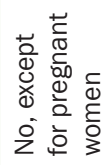 & 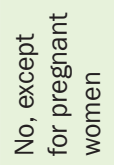 & 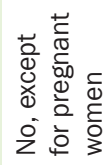 & 운 \\
\hline の & $\stackrel{\mathscr{N}}{\nu}$ & z & $\stackrel{\mathscr{\nu}}{\varnothing}$ & $\stackrel{\infty}{\varnothing}$ & $\stackrel{\infty}{\nu}$ & $\stackrel{\mathscr{D}}{\nu}$ & $\stackrel{\infty}{\nu}$ & $\stackrel{\infty}{\varnothing}$ & $\stackrel{\infty}{\varnothing}$ & $\stackrel{\infty}{ٍ}$ & $\stackrel{\mathscr{D}}{\nu}$ & $\stackrel{\mathscr{0}}{\varnothing}$ & $\stackrel{\mathscr{D}}{\rightleftharpoons}$ \\
\hline 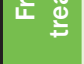 & $\stackrel{\mathscr{N}}{\succ}$ & z & $\stackrel{0}{z}$ & $\stackrel{\infty}{\nu}$ & $\stackrel{0}{z}$ & $\stackrel{\infty}{\nu}$ & ્ֻర & $\stackrel{\mathscr{D}}{\varnothing}$ & z & $\stackrel{\mathscr{N}}{\rightleftharpoons}$ & zo & $\stackrel{\infty}{\rightleftharpoons}$ & $\stackrel{\circ}{z}$ \\
\hline ङूँ & $\stackrel{\mathscr{D}}{\varnothing}$ & z & $\stackrel{\mathscr{\nu}}{\nearrow}$ & zo & $\stackrel{\infty}{\nu}$ & z & $\stackrel{\infty}{\nu}$ & $\stackrel{0}{\nu}$ & z & z & zo & $\stackrel{\circ}{z}$ & $\stackrel{0}{z}$ \\
\hline 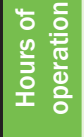 & 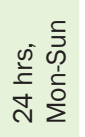 & 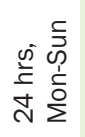 & 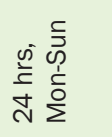 & 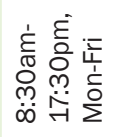 & 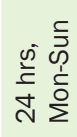 & 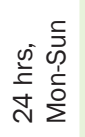 & 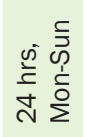 & 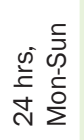 & 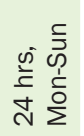 & 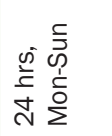 & 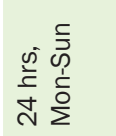 & 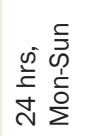 & 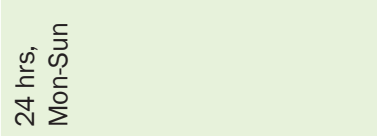 \\
\hline 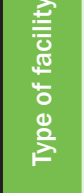 & 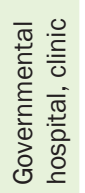 & 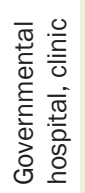 & 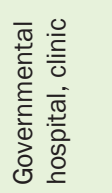 & $\begin{array}{l}\text { O } \\
0 \\
0 \\
\vdots \\
0 \\
0 \\
0\end{array}$ & 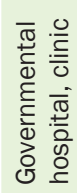 & 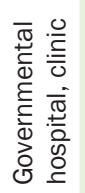 & 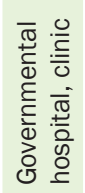 & $\begin{array}{l}\text { Oे } \\
0 \\
\dot{0} \\
0 \\
0 \\
\frac{0}{2}\end{array}$ & 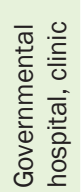 & 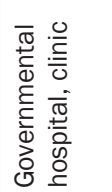 & 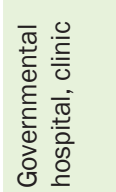 & 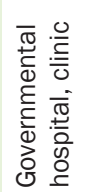 & 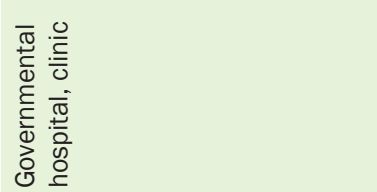 \\
\hline 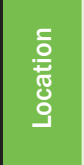 & $\begin{array}{l}\frac{\pi}{0} \\
\frac{0}{0} \\
\frac{8}{4} \\
\frac{0}{0} \\
\frac{0}{8}\end{array}$ & $\begin{array}{l}\frac{\pi}{0} \\
\frac{0}{10} \\
\frac{0}{1} \\
\frac{0}{7} \\
\frac{0}{2}\end{array}$ & $\begin{array}{l}\frac{\pi}{0} \\
\frac{0}{\pi} \\
\frac{0}{4} \\
\frac{0}{\overline{0}} \\
\frac{0}{2}\end{array}$ & $\begin{array}{l}\frac{\pi}{0} \\
\frac{\pi}{\pi} \\
\frac{0}{4} \\
\frac{0}{10} \\
\frac{7}{4}\end{array}$ & $\begin{array}{l}\frac{\pi}{0} \\
\frac{0}{\pi} \\
\frac{8}{4} \\
\frac{0}{0} \\
\frac{0}{4}\end{array}$ & $\begin{array}{l}\frac{0}{0} \\
\frac{0}{0} \\
\frac{8}{4} \\
\frac{0}{0} \\
\frac{0}{0}\end{array}$ & $\begin{array}{l}\frac{\pi}{0} \\
\frac{0}{\pi} \\
\frac{0}{\mathbb{2}} \\
\frac{0}{\overline{0}} \\
\frac{0}{4}\end{array}$ & $\begin{array}{l}\frac{\pi}{0} \\
\frac{0}{0} \\
\frac{\pi}{4} \\
\frac{\omega}{0} \\
\frac{0}{4}\end{array}$ & $\begin{array}{l}\frac{\pi}{0} \\
\frac{0}{\pi} \\
\frac{0}{1} \\
\frac{0}{\overline{0}} \\
\frac{0}{4}\end{array}$ & $\begin{array}{l}\frac{\pi}{0} \\
\frac{0}{\pi} \\
\frac{0}{1} \\
\frac{0}{\overline{0}} \\
\frac{0}{0}\end{array}$ & $\begin{array}{l}\frac{\pi}{0} \\
\frac{0}{\pi} \\
\frac{8}{8} \\
\frac{0}{0} \\
\frac{0}{0}\end{array}$ & $\begin{array}{l}\frac{\pi}{0} \\
\frac{0}{\pi} \\
\frac{0}{0} \\
\frac{0}{0} \\
\frac{0}{4}\end{array}$ & $\begin{array}{l}\frac{\pi}{0} \\
\frac{0}{0} \\
\frac{\pi}{4} \\
\frac{0}{7} \\
\frac{0}{4}\end{array}$ \\
\hline 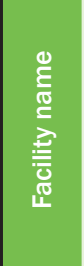 & 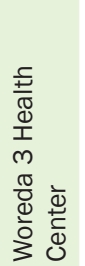 & 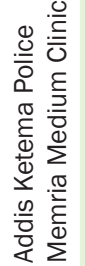 & 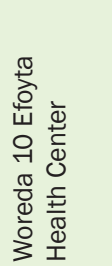 & 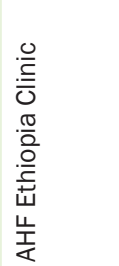 & 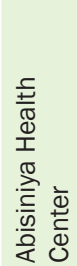 & 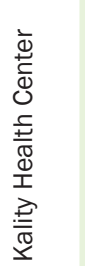 & 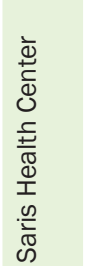 & 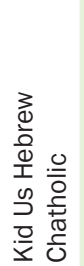 & 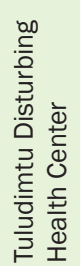 & 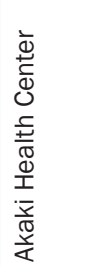 & 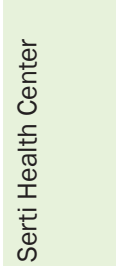 & 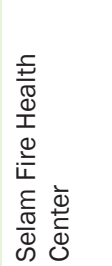 & 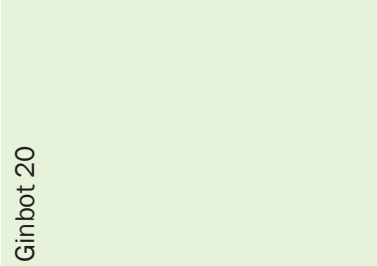 \\
\hline
\end{tabular}




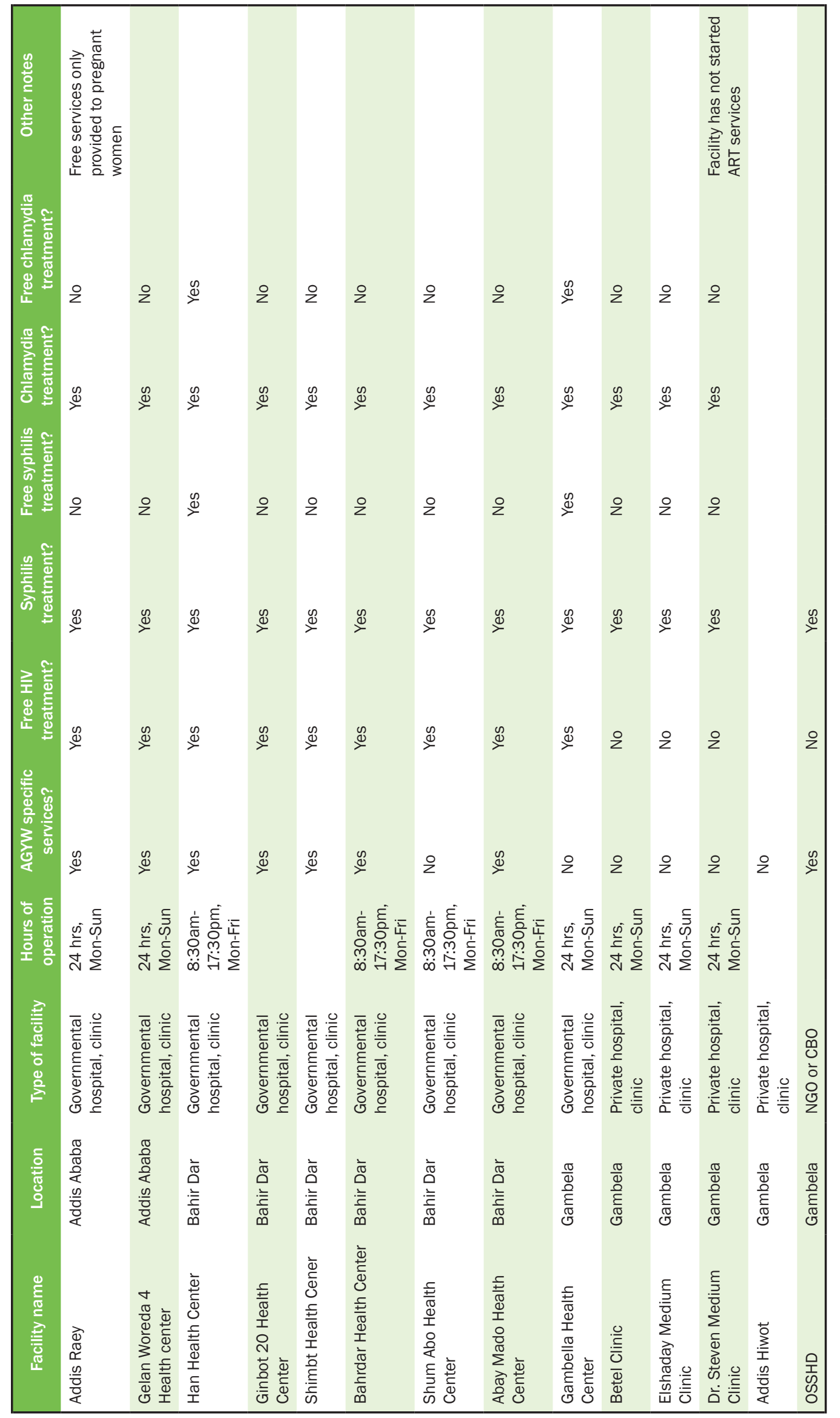



Project SOAR

Population Council 4301 Connecticut Ave, NW,

Suite 280

Washington, D.C. 20008 USA

Tel: +1 2022379400

Fax: +1 2022378410

Ideas. Evidence. Impact.

projsoar.org 